\title{
Multiorgan failure with abnormal receptor metabolism in mice mimicking Samd9/9L syndromes
}

\author{
Akiko Nagamachi, ${ }^{1}$ Akinori Kanai, ${ }^{1}$ Megumi Nakamura, ${ }^{1}$ Hiroshi Okuda, ${ }^{2}$ Akihiko Yokoyama, ${ }^{2,3}$ Satoru Shinriki, ${ }^{4}$ Hirotaka Matsui, ${ }^{4}$ \\ and Toshiya Inaba' \\ 'Department of Molecular Oncology and Leukemia Program Project, Research Institute for Radiation Biology and Medicine, Hiroshima University, Hiroshima, Japan. ${ }^{2}$ Tsuruoka Metabolomics Laboratory, \\ National Cancer Center, Tsuruoka, Yamagata, Japan. ${ }^{3}$ National Cancer Center Research Institute, Tokyo, Japan. ${ }^{4}$ Department of Molecular Laboratory Medicine, Faculty of Life Sciences, Kumamoto University, \\ Kumamoto, Japan.
}

\begin{abstract}
Autosomal dominant sterile $\alpha$ motif domain containing 9 (Samd9) and Samd9L (Samd9/9L) syndromes are a large subgroup of currently established inherited bone marrow failure syndromes that includes myelodysplasia, infection, growth restriction, adrenal hypoplasia, genital phenotypes, and enteropathy (MIRAGE), ataxia pancytopenia, and familial monosomy 7 syndromes. Samd9/9L genes are located in tandem on chromosome 7 and have been known to be the genes responsible for myeloid malignancies associated with monosomy 7. Additionally, as IFN-inducible genes, Samd9/9L are crucial for protection against viruses. Samd9/9L syndromes are caused by gain-of-function mutations and develop into infantile myelodysplastic syndromes associated with monosomy 7 (MDS/-7) at extraordinarily high frequencies. We generated mice expressing Samd9L ${ }^{\mathrm{D} 64 \mathrm{~N}}$, which mimic MIRAGE syndrome, presenting with growth retardation, a short life, bone marrow failure, and multiorgan degeneration. In hematopoietic cells, Samd9L ${ }^{\mathrm{D} 64 \mathrm{~N}}$ downregulates the endocytosis of transferrin and c-Kit, resulting in a rare cause of anemia and a low bone marrow reconstitutive potential that ultimately causes MDS/-7. In contrast, in nonhematopoietic cells we tested, Samd9L ${ }^{\mathrm{D} 64 \mathrm{~N}}$ upregulated the endocytosis of EGFR by Ship2 phosphatase translocation to the cytomembrane and activated lysosomes, resulting in the reduced expression of surface receptors and signaling. Thus, Samd9/9L is a downstream regulator of IFN that controls receptor metabolism, with constitutive activation leading to multiorgan dysfunction.
\end{abstract}

\section{Introduction}

Inherited bone marrow failure syndromes (IBMFs) are a heterogeneous group of disorders, mostly caused by a single gene abnormality (1). Identification and characterization of the causative genes have greatly affected research on not only hematopoiesis, but also fundamental biological pathways. In addition, because IBMFs are frequently associated with nonhematopoietic disorders and a propensity to cancer, they provide insights into normal and perturbed regulation of cell growth and differentiation in various organs.

Autosomal dominant sterile $\alpha$ motif domain containing 9 (Samd9) and Samd9L (Samd9/9L) syndromes are a subgroup of currently established IBMFs $(1,2)$ that includes myelodysplasia, infection, growth restriction, adrenal hypoplasia, genital phenotypes, and enteropathy (MIRAGE) $(3,4)$, ataxia pancytopenia (AP) $(5,6)$, and familial monosomy 7 syndromes (7). Patients with Samd9/9L syndrome carry a gain-of-function ( $\mathrm{g} / \mathrm{f}$ ) mutation of Samd9 or its related Samd $9 \mathrm{~L}$ gene, both of which are located in tandem on chromosome 7. Samd9/9L syndromes make up nearly $20 \%$ of IBMFs, emerging as one of its largest subgroups (1).

Conflict of interest: The authors have declared that no conflict of interest exists. Copyright: () 2021, American Society for Clinical Investigation.

Submitted: May 12, 2020; Accepted: December 10, 2020; Published: February 15, 2021. Reference information: J Clin Invest. 2021;131(4):e140147.

https://doi.org/10.1172/JCl140147.
The Samd 9 gene was first described in a paper as a causal gene for autosomal recessive normophosphatemic familial tumoral carcinosis (NFTC) (8). Loss-of-function mutations of Samd9 were identified in patients with NFTC, which is characterized by skin inflammation induced by excessive signaling via IFN- $\gamma$ pathways. Indeed, Samd9/9L genes were later identified as IFN-inducible genes (9), since the mouse Samd9L gene has IFN-responsive cis elements in the promoter, to which IFN regulatory factor 1 binds (10). In addition, Samd9/9L suppresses the replication of viruses, including Japanese encephalitis virus (11), and serves as a barrier for cross-species poxvirus transmission (12-14).

Samd9/9L genes have been identified as the genes responsible for monosomy 7 , one of the most frequent chromosomal abnormalities in myeloid malignancies, particularly in myelodysplastic syndromes (MDS). Samd9/9L genes are included in microdeletions of chromosome 7 and are occasionally detected in children with leukemia/leukoproliferative diseases who carry apparently normal chromosome 7 (15). In addition, more than half of either Samd9L homo- or heterodeficient mice spontaneously develop MDS (16), suggesting that Samd9/9L proteins are myeloid tumor suppressors that act in a haploinsufficient manner.

The most striking feature of Samd9/9L syndromes is an extraordinarily high frequency of MDS associated with monosomy 7 (MDS/-7) or an interstitial deletion of the long arm of chromosome 7. The age of onset is mostly less than 5 years, and quite unusually, the mutated allele is always lost in MDS cells. Because 
A
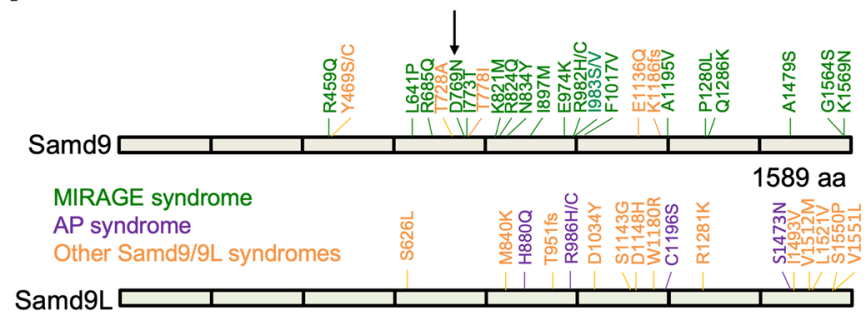

1584 aa
B
C

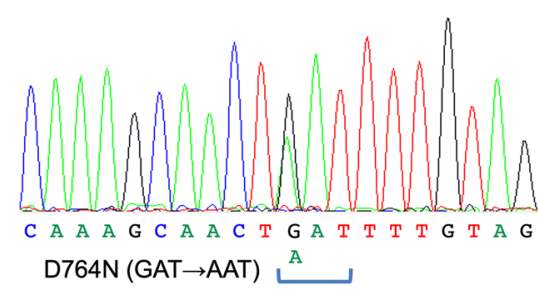

$\mathbf{E}$

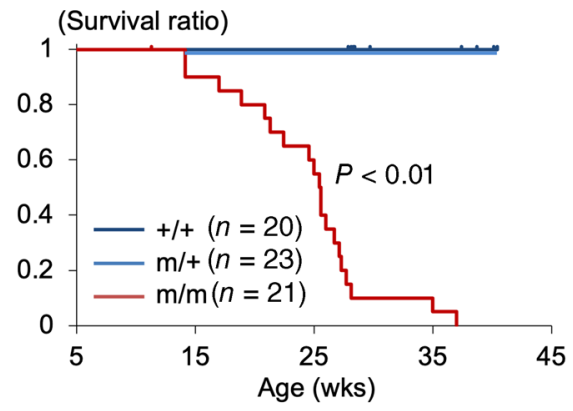

G

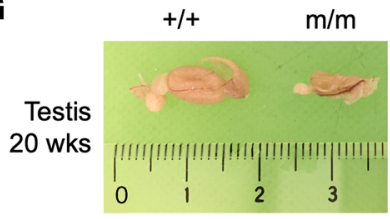

D
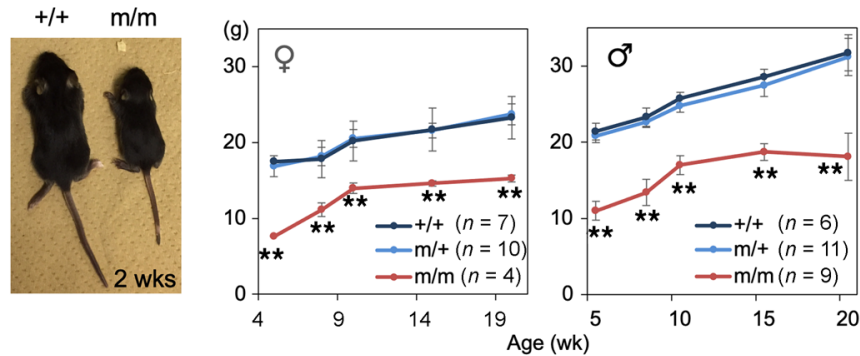

$\mathbf{F}$
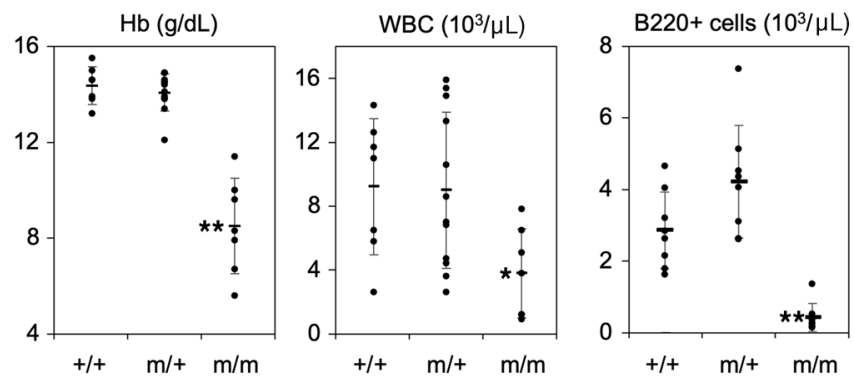

H

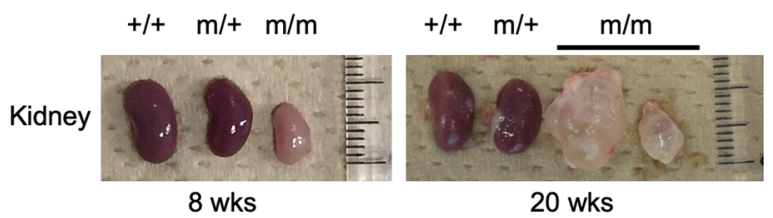

Figure 1. Characterization of mice expressing Samd9L ${ }^{\mathbf{0 7 6 4 N}}$ mutant. (A) Schematic of human Samd9/9L proteins. Mutations identified in patients with MIRAGE, AP, and other members of Samd9/9L syndromes are indicated. (B) Alignment of amino acid sequence of mammalian Samd9/9L surrounding the mutation site (red). Dots indicate amino acid residues identical to those of human Samd9. (C) Sequencing analysis of tail DNA from micem/+. (D) Photograph of siblings at 2 weeks of age. Genotypes are indicated above (left). Body weights of mice ${ }^{+/+}$, mice ${ }^{\mathrm{m} /+}$, and mice ${ }^{\mathrm{m} / \mathrm{m}}$. Means are plotted, and error bars show SD. (E) Survival curves after postnatal day 28. Significance was calculated by log-rank test. (F) Peripheral blood counts at 25 weeks of age. Horizontal line indicates the mean, vertical the SD. Eight mice in each group. (G and H) Photographs of mouse testes with epididymis after formalin fixation (G) and kidneys immediately after dissection (H). Genotypes and ages are indicated in the figure. ${ }^{*} P<0.05 ;{ }^{*} P<0.01$, Tukey-Kramer test $(\mathbf{D}$ and $\mathbf{F})$.

mutations of Samd9/9L that cause IBMF have an adverse effect on cell proliferation, it is conceivable that the loss of mutated Sam$d 9 / 9 \mathrm{~L}$ genes rescues the growth potential of bone marrow cells by an adaption by aneuploidy (3) mechanism and creates a condition known as revertant mosaicism (4). These findings suggest that Samd9/9L contributes to the homeostasis of hematopoiesis as a suppressor of MDS, whereas the excess function of Samd9/9L mutants suppresses hematopoiesis to cause IBMFs.

As with other disease entities that cause IBMF, patients with Samd9/9L syndromes frequently show nonhematopoietic symptoms. For instance, patients with MIRAGE syndrome caused by
SAMD9 missense mutations show systemic symptoms such as growth retardation and a short life as well as characteristic multiorgan failures, including adrenal dysfunction, hypogonadism, and immunological dysfunction $(3,4)$, while patients with AP syndrome caused by Samd $9 \mathrm{~L}$ missense mutations develop severe cerebellum atrophy $(5,6)$. These clinical observations suggest common molecular mechanisms throughout tissues and organs that are affected by the dysfunction of Samd9/9L.

To elucidate this, we established mice carrying a Samd $9 \mathrm{~L}$ mutation that have a phenotype resembling MIRAGE syndrome. Analysis of this mouse model has highlighted how the key to 
understanding the mechanism of Samd9/9L dysfunction is the internalization and degradation of cell-surface receptors.

\section{Results}

Mice carrying a Samd9L mutation mimic MIRAGE syndrome. A large number of missense mutations of Samd9/9L genes have been identified throughout the protein in patients with Samd9/9L syndromes (Figure 1A) $(1,3-7,17-26)$. We selected Samd9 ${ }^{\text {D769N }}$ in a pedigree of MIRAGE syndrome, in which 2 patients developed infantile MDS (3). Because the flanking region of this mutation site is well conserved between human Samd9 and mouse Samd9L as well as Samd9/9L proteins of many other mammals (Figure $1 B)$, we surmised that the mouse equivalent, Samd9L ${ }^{\mathrm{D} 764 \mathrm{~N}}$, had effects similar to those of human Samd9 ${ }^{\mathrm{D} 769 \mathrm{~N}}$ (note that the mouse genome does not have a Samd9 gene).

Using CRISPR/Cas9 technology (27), we generated D764N hemizygotes $\left(\right.$ mice $^{\mathrm{m} /+}$ ) by targeting genes in F2-fertilized oocytes by the pronuclear injection of Cas 9 protein and gene-specific guide RNA. Two male mouse ${ }^{\mathrm{m} /+}$ founders were able to breed, and female heterozygous offspring were checked by sequencing (Figure 1C); these were used for further breeding of the line. When mating male and female mice ${ }^{\mathrm{m} /+}$, roughly a quarter of offspring were small, one-third of which died before weaning, although they had been active. All small mice that survived weaning were subsequently shown to be D764N homozygotes (mice ${ }^{\mathrm{m} / \mathrm{m}}$; Figure 1D). These mice were active for more than 2 months, but started to die after 15 weeks of age, mostly dying within 28 weeks (Figure $1 \mathrm{E}$ ). To generate $\operatorname{Samd} 9 \mathrm{~L}^{\mathrm{m} /-}$ mice, we mated mice $^{\mathrm{m} /+}$ with $S a m d 9 L$-deficient mice $\left(\right.$ mice $\left.^{-/}\right)$, which frequently develop spontaneous MDS (16). The mice ${ }^{\mathrm{m} /+}$ and mice ${ }^{\mathrm{m} /-}$ showed no apparent abnormalities.

Mice $^{\mathrm{m} / \mathrm{m}}$ developed anemia, a common symptom of Samd9/9L syndromes and B lymphocytopenia, which has also been observed in some MIRAGE syndrome patients (Figure 1F). Thymi of 15-week-old mice looked normal, but shrank rapidly by 20 weeks. Although 10 -week-old male mice ${ }^{\mathrm{m} / \mathrm{m}}$ were fertile, their testes rapidly underwent atrophy thereafter (Figure 1G). Kidneys were pale at 8 weeks and thereafter underwent cystic degeneration (Figure 1H). Such a harsh phenotype has not been reported in MIRAGE syndrome, probably because mouse kidney expresses Samd9L at the highest level among all organs tested (28) in contrast to human kidney, which expresses Samd9 at the lowest level (4). Whereas newborn adrenal insufficiency is a characteristic of MIRAGE syndrome, the adrenal glands of mice ${ }^{\mathrm{m} / \mathrm{m}}$ were of an apparently normal size.

Delayed internalization of TfRs in erythroblasts of mice $\mathrm{m} / \mathrm{m}$. The anemia that developed in mice ${ }^{\mathrm{m} / \mathrm{m}}$ was hypochromic and mildly microcytic (Figure 2A). Unlike patients with Samd9/9L syndromes, mice ${ }^{\mathrm{m} /+}$ showed normal RBC indices. To evaluate the implications of normal and mutated Samd9L on erythropoiesis, mice $^{-/-}$, mice $^{+/+}$, mice $^{\mathrm{m} / \mathrm{m}}$, and mice ${ }^{\mathrm{m} /+}$ were i.p. injected with an IFN inducer, polyinosinic-polycytidylic acid (Poly[I:C]), as Sam$d 9 L$ is an IFN-inducible gene $(9,10)$. Enhanced expression of Samd9L protein was shown in the kidney of mice it/ $^{+}$and mice $\mathrm{e}^{\mathrm{m} /+}$ by the injection of Poly(I:C) twice a week for 1 month (Figure 2B), although mice $^{\mathrm{m} / \mathrm{m}}$ rapidly deteriorated to death after a couple of injections. A rapid decline of hemoglobin $(\mathrm{Hb})$ and mean corpuscular volume (MCV) was observed in mice $^{+/+}$and more severely in mice $^{\mathrm{m} /+}$, but not in mice ${ }^{-/-}$(Figure 2C), suggesting that the excess expression of Samd9L inhibits erythropoiesis with enhanced effects by D764N mutation. These data also highlighted the fragility of hematopoiesis in mice m/t+ $^{\mathrm{m}}$.

Serum iron concentrations were normal, but serum erythropoietin (Epo) levels of mice ${ }^{\mathrm{m} / \mathrm{m}}$ and mice ${ }^{\mathrm{m} /+}$ were elevated (Figure 2D) at 25 weeks, indicating that the anemia was not due to low Epo production because of renal failure. The bone marrow was normocellular (Figure 2E) with an increased ratio of proerythroblasts and basophilic erythroblasts, although substantial differences existed among mice, with approximately one-fourth of mice having hypocellular bone marrow. Flow cytometric analysis (FCM) using antibodies against the transferrin receptor (TfR; CD71), and a Ter119 antibody that recognized glycophorin-A-related erythroid-specific surface protein revealed high TfR expression in Ter119-positive erythroblasts and erythrocytes in both bone marrow cells and splenocytes (Figure 2F). Using a CD44 antibody, according to cell size (forward scatter), Ter119-positive cells were further fractionated (Figure 2G) (29, 30). This procedure revealed high TfR expression in basophilic and polychromatic erythroblasts ${ }^{\mathrm{m} / \mathrm{m}}$.

These data demonstrated that Samd $9 \mathrm{~L}^{\mathrm{D} 764 \mathrm{~N}}$ induced a very rare hypochromic/microcytic anemia with normal serum iron, high serum Epo concentrations, and high surface TfR of erythroblasts. We noticed that this pattern of anemia had also occurred in mice lacking the Picalm gene $(31,32)$, which encodes a phosphatidylinositol-binding (PI-binding) clathrin assembly protein that drives coated pit formation in the process of clathrin-mediated endocytosis (CME) (33). Picalm-deficient mice not only show a rare type of anemia, but also have small bodies and short lives, similarly to mice $\mathrm{m}^{\mathrm{m} / \mathrm{m}}$, suggesting that Samd9 $\mathrm{L}^{\mathrm{D} 764 \mathrm{~N}}$ inhibits iron uptake through suppressing Picalm function. Indeed, immunofluorescence (IF) staining using a monoclonal antibody (A6m) against mouse Samd9L detected the abundant expression of Samd9L in Ter119-positive splenocytes from mice (but not from mice $^{-/-}$), which also showed high expression of Picalm clathrin and TfR (Supplemental Figure 1; supplemental material available online with this article; https://doi.org/10.1172/JCI140147DS1).

Since erythroblasts of Picalm-deficient mice show the slowed endocytosis of transferrin (Tf) and TfR $(31,32)$, we undertook FCMbased specific hybridization internalization probe (SHIP) analysis (34) to measure steady-state surface receptor internalization rates ex vivo. $\mathrm{Tf}$ and $\mathrm{TfR}$ were rapidly internalized in erythroblasts ${ }^{+/+}$, as previously reported (Figure $2 \mathrm{H}$ ) (34), with similar internalization rates observed in erythroblasts ${ }^{-/}$. Endocytosis was delayed in erythroblasts $^{\mathrm{m} / \mathrm{m}}$, indicating that Samd9 $\mathrm{L}^{\mathrm{D} 764 \mathrm{~N}}$ is a suppressor of CME.

Low bone marrow reconstitutive potential of Samd $9 L^{D 764 N}$-expressing immature hematopoietic progenitors. We next analyzed hematopoietic stem cells (HSCs) and hematopoietic stem/progenitor cells (HSPCs). We previously reported that HSPCs expressed Samd9L transcripts, and the total number and proportion of 3 subsets within the c-Kit ${ }^{+} \mathrm{Lin}^{-} \mathrm{Sca}-1^{+}$(KLS) fraction (long-term [LT] HSCs, CD34-flt3-; short-term [ST] HSCs, CD34+flt3-; multipotent progenitor $\left.[\mathrm{MPP}], \mathrm{CD}^{+} 4^{+} \mathrm{flt}^{+}\right)$(35) were not altered between mice $^{+/+}$and mice $^{-/-}$(16). Differences in the total number and proportion of HSCs were not observed among mice $^{+/+}$, mice $^{\mathrm{m} /+}$, and mice $^{\mathrm{m} / \mathrm{m}}$ (Figure 3A). However, significant differences in lineage committed precursors were observed in that the numbers of eryth- 
A
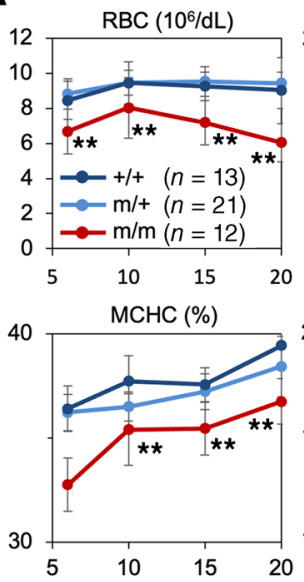

C
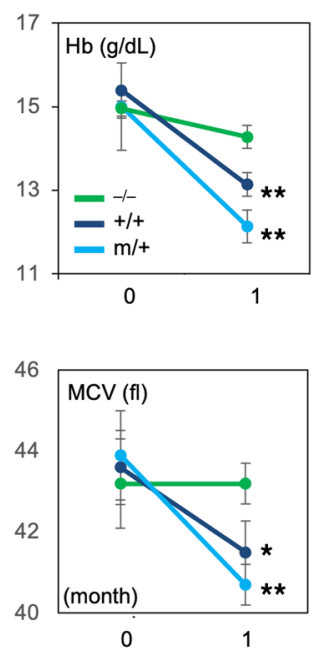

$\mathrm{Hb}(\mathrm{g} / \mathrm{dL})$

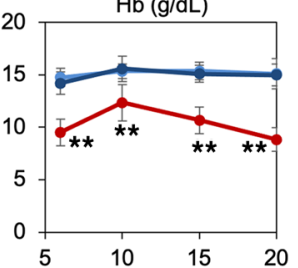

$\mathrm{MCH}(\mathrm{pg})$

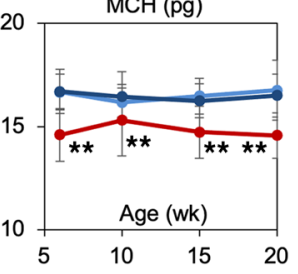

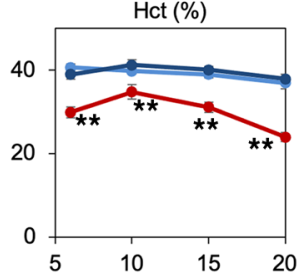

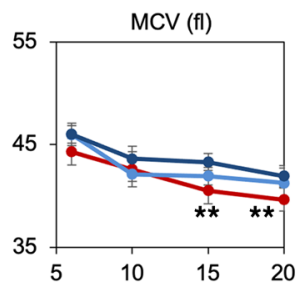

B
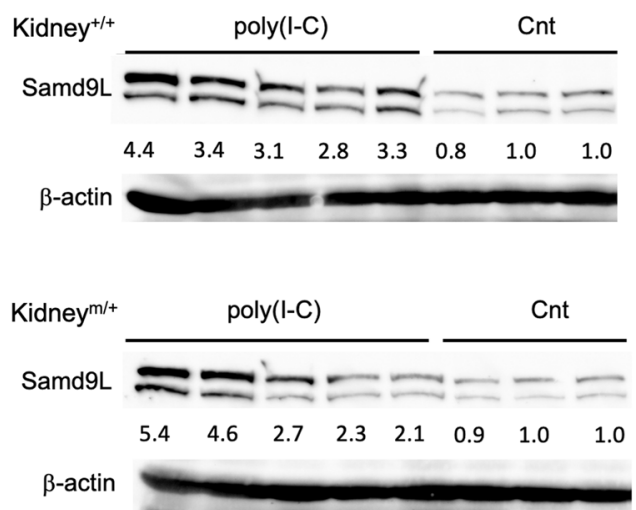

$\mathbf{F}$

E

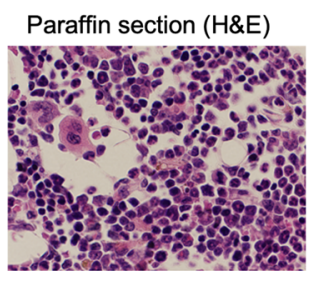

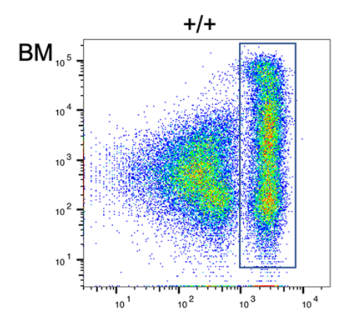
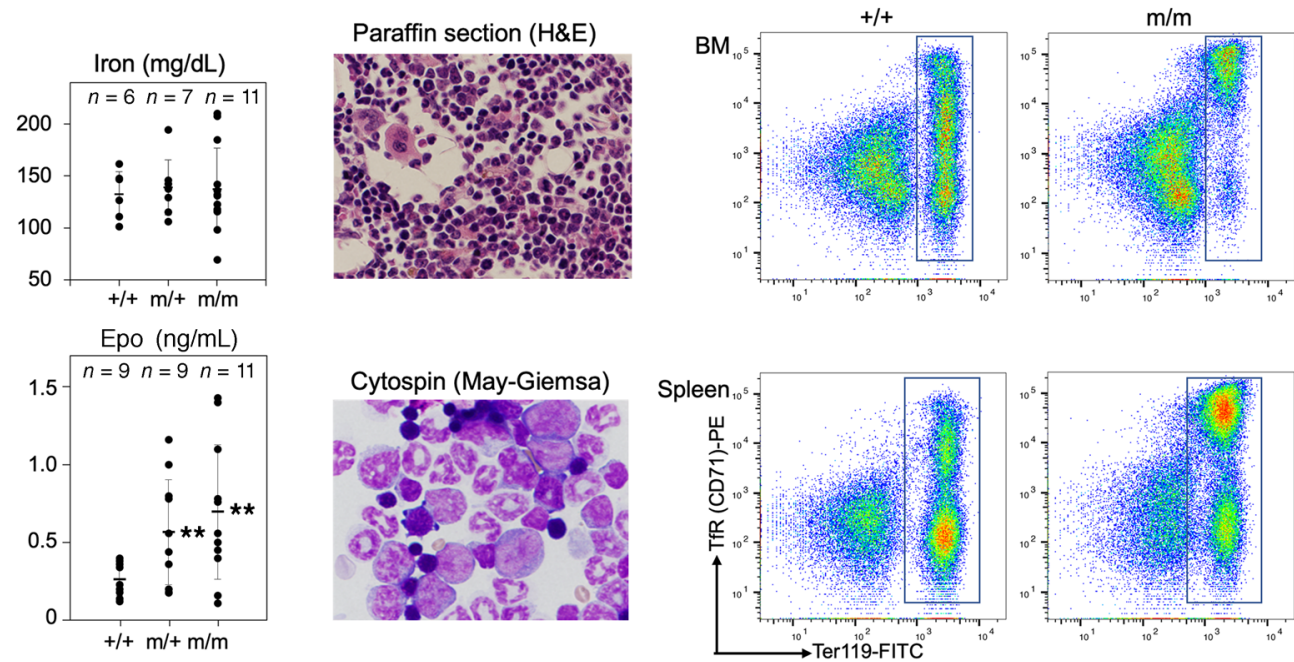

G
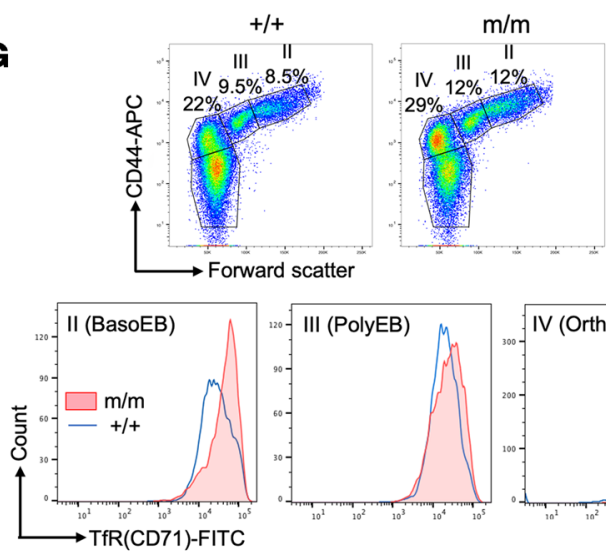
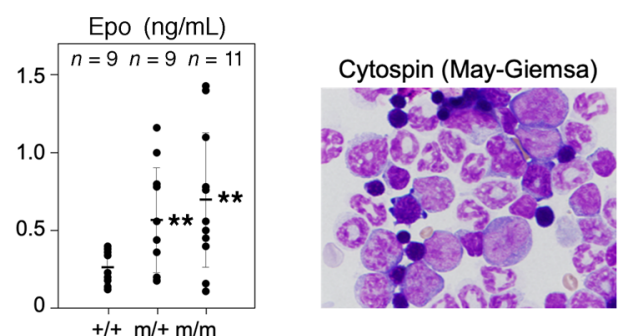

H

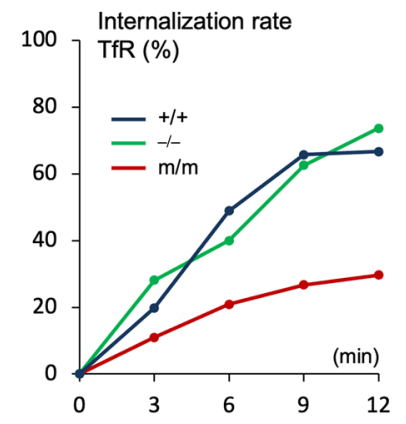

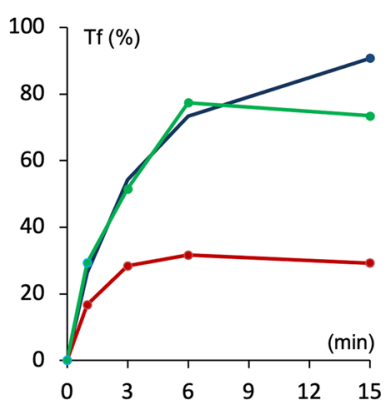

Figure 2. Low Tf/TfR internalization rates in EB ${ }^{m / m}$. (A) RBC indices. MCHC, mean corpuscular Hb concentration; MCH, mean corpuscular Hb. (B-C) Eightweek-old mice were subjected to an i.p. injection of poly(l:C) twice a week for 1 month. Immunoblots of kidney extracts using antibodies at left. Expression levels relative to untreated mice (Cnt) are shown between 2 panels (B). Hb and MCV. $n=5$ for each group (C). (D) Serum iron (upper) or Epo (lower) concentrations of 25-week-old mice. Horizontal lines indicate the mean, vertical the SD. (E) H\&E staining of a paraffin section (upper) and a May-Giemsa stained cytospin preparation (lower) of representative bone marrow from 10-week-old mice ${ }^{\mathrm{m} / \mathrm{m}}$. Original magnification, $\times 200$ (upper panel), $\times 1000$ (lower panel). (F) Representative FCM plots (of 4 independent experiments) of bone marrow (upper) or splenic cells (lower) from 5-week-old mice using TfR and Ter119 antibodies. Insets: Ter119-positive erythroblasts and erythrocytes. (C) Representative FCM plots (of 3 independent experiments) of bone marrow cells from 5-week-old mice showing basophilic (BasoEB, II), polychromatic (PolyEB, III), and orthochromatic erythroblasts (OrthoEB, IV) (29, 30) by staining of Ter119-positive cells (F) with a CD44 antibody and forward scatter (upper). Representative FCM histograms of TfR in each fraction (lower). (H) SHIP analysis of TfR (left) or Tf (right) internalization in bone marrow Ter119-positive erythroblasts from 5-week-old mice. Representative results are shown. Similar results were obtained in 4 independent experiments. Means are plotted, and error bars show SD in (A, C, and $\mathbf{D})$. ${ }^{*} P<0.05$; ${ }^{* *} P<0.01$, Tukey's test (C); Tukey-Kramer test (A and $\left.\mathbf{D}\right)$. 
A

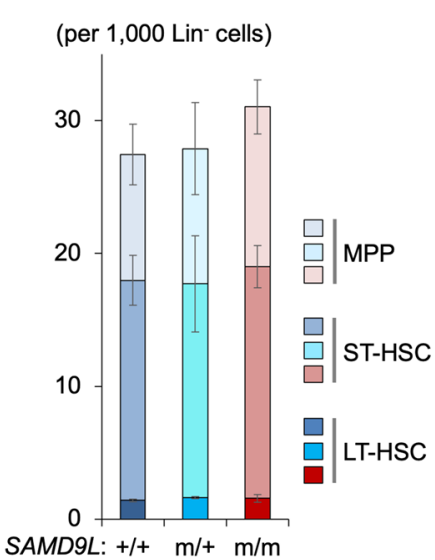

D
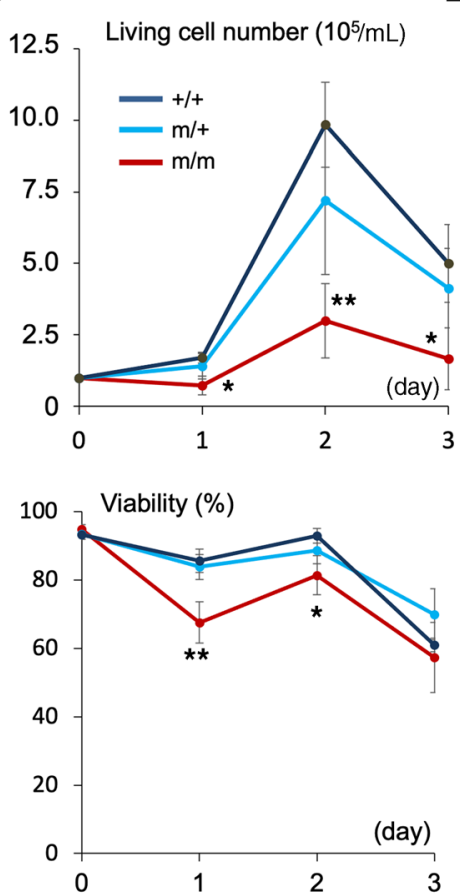

B
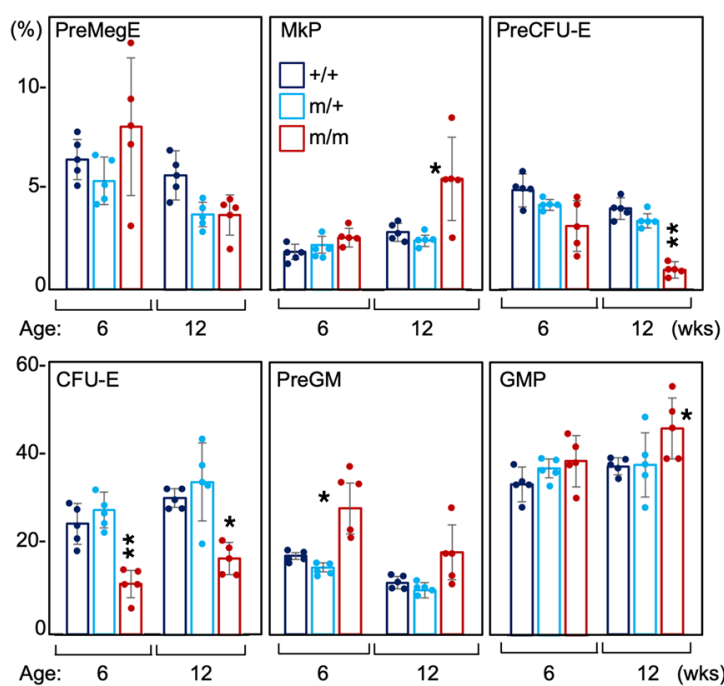

C

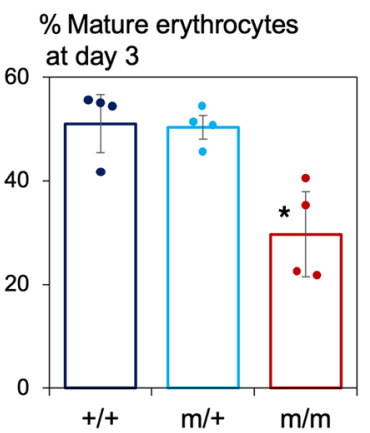

E
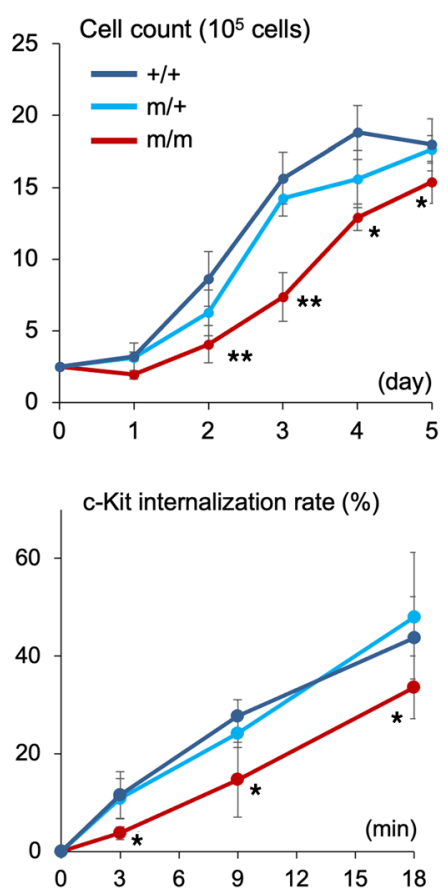

$\mathbf{F}$

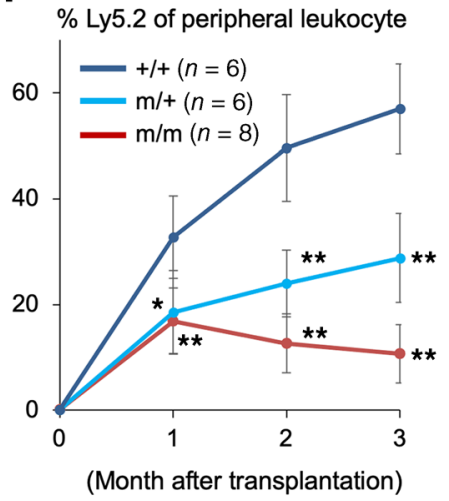

G

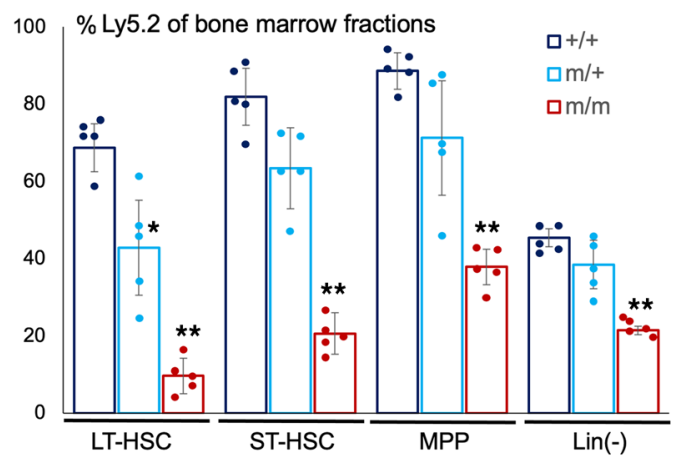

Figure 3. Characterization of hematopoietic progenitors. (A) The numbers of cells in a KLS population (LT-HSCs, CD34-flt3-; ST-HSCs, CD34+flt3-; MPP, $\mathrm{CD}^{+} 4^{+} \mathrm{flt}^{+}$) (35) per 1000 bone marrow cells. Means and SD of 4 mice at 10 weeks of age. (B) Percentage of progenitors in a Lin/Sca-1/IL-7R $\alpha-\mathrm{C}-\mathrm{Kit}{ }^{+}$population (54). Mean and SD of 5 mice are shown. (C-D) KL cells were cultured in Epo for 3 days. The numbers of mature erythrocytes (FSC $\left.{ }^{10}, S^{2} C^{10}\right)$ at day 3 (C). Living cell numbers and percentages of dead cells during culture were determined by trypan blue dye exclusion (D). Mean and SD of 5 mice at 8 weeks of age are shown. (E) Bone marrow cells from either mice ${ }^{+/+}$or mice $\mathrm{m} / \mathrm{m}$ containing $\mathrm{mSCF}$ and TPO were cultured for 5 days. KL cells were isolated and continued in culture for an additional 5 days. Cell count (upper) and results of SHIP analysis for c-Kit internalization (lower). Mean and SD of 5 mice at 9 weeks of age are shown. ( $\mathbf{F}$ and $\mathbf{G})$ Reconstitutive potential using the Ly5 congenic mouse system and LT-HSC cells isolated from 9-week-old mice. The percentages of donor-derived (Ly5.2+) cells in the total WBCs in the peripheral blood at the periods indicated after transplantation. Means are plotted, and error bars show SD (F). The ratio of Ly5.2-positive cells in LT-HSC, ST-HSC, MPP, and Lin-negative cells in bone marrow of recipient mice 3 months after transplantation. Means and SD of 5 mice are shown (G). ${ }^{*} P<0.05 ;{ }^{*} P<0.01$, Tukey's test (B-E and $\left.\mathbf{C}\right)$; Tukey-Kramer test (F).

roid progenitors (pre-CFU-erythroid [pre-CFU-E] and CFU-E) were decreased in mice ${ }^{\mathrm{m} / \mathrm{m}}$ compared with mice $^{\mathrm{m} /+}$ or mice $^{+/+}$ (Figure 3B) despite high serum Epo levels (Figure 2D), suggesting that the response to Epo was reduced in the bone marrow cells of mice ${ }^{\mathrm{m} / \mathrm{m}}$. To test this, isolated c-Kit ${ }^{+} \mathrm{Lin}^{-}(\mathrm{KL})$ cells from mice ${ }^{+/}$, mice $^{\mathrm{m} /+}$, or mice ${ }^{\mathrm{m} / \mathrm{m}}$ were cultured in medium containing Epo for 3 days to produce mature erythrocytes (32). Cultured isolated $\mathrm{KL}^{\mathrm{m} / \mathrm{m}}$ cells generated mature erythrocytes less efficiently than $\mathrm{KL}^{+/}$or 
$\mathrm{KL}^{\mathrm{m} /+}$ cells (Figure $3 \mathrm{C}$ ). The growth and viability of $\mathrm{KL}^{\mathrm{m} / \mathrm{m}}$ cells was significantly downregulated (Figure 3D), highlighting the poor response of $\mathrm{KL}^{\mathrm{m} / \mathrm{m}}$ cells to Epo.

We then tested responses to stem cell factor (SCF) and thrombopoietin (TPO). Bone marrow cells from either mice ${ }^{+/+}$, mice $^{\mathrm{m} /+}$, or mice ${ }^{\mathrm{m} / \mathrm{m}}$ were cultured in medium containing SCF and TPO for 5 days. KL cells were then isolated $\left(\mathrm{KL}-5 \mathrm{~d}^{+/+}, \mathrm{KL}-5 \mathrm{~d}^{\mathrm{m} /+}\right.$, and $\mathrm{KL}-5 \mathrm{~d}^{\mathrm{m} / \mathrm{m}}$ ) and continued to be cultured for an additional 5 days. $\mathrm{KL}-5 \mathrm{~d}^{\mathrm{m} / \mathrm{m}}$ cells grew more slowly than $\mathrm{KL}-5 \mathrm{~d}^{+/+}$cells (Figure $3 \mathrm{E}$ ), suggesting low sensitivities to the SCF/TPO of HSPCs of mice $\mathrm{m}^{\mathrm{m} / \mathrm{m}}$. We then applied SHIP analysis to measure the endocytosis of c-Kit in KL-5d cells. The slower endocytosis of c-Kit compared with control KL-5 $\mathrm{d}^{+/+}$cells was observed in $\mathrm{KL}^{2} \mathrm{~d}^{\mathrm{m} / \mathrm{m}}$, but not in $\mathrm{KL} 5 \mathrm{~d}^{\mathrm{m} /+}$, cells (Figure 3E).

One prominent feature of patients with Samd9/9L syndrome is the frequent development of MDS associated with $-7 / \operatorname{del}(7 \mathrm{q})$, in which mutated Samd9/9L is lost. However, mice ${ }^{\mathrm{m} /+}$ or mice $\mathrm{m}^{\mathrm{m} / \mathrm{m}}$ did not show any signs of myeloid malignancies during their life spans. We measured the frequency of cells carrying a loss of the Samd9L gene in the bone marrow of aged mice ( $>24$ weeks) using interphase FISH analysis. Myeloid, erythroid, or lymphoid lineage bone marrow cells of mice $\mathrm{m}^{\mathrm{m} /+}$ or mice $\mathrm{m}^{\mathrm{m} / \mathrm{m}}$ did not show increased frequencies of cells carrying a loss of the Samd9L gene over those of mice $^{+/+}$(Supplemental Figure 2).

Finally, we analyzed the bone marrow reconstitutive potential of HSCs by performing a bone marrow competitive repopulation assay using an Ly5 congenic mouse system. Irradiated Ly5.1 mice were transplanted with an LT-HSC fraction from either Ly5.2 mice $^{\mathrm{m} / \mathrm{m}}$, Ly5.2 mice $^{\mathrm{m} /+}$, or Ly5.2 mice $^{+/+}$together with bone marrow cells from Ly5.1 mice me $^{+/}$. A markedly reduced potential was observed in $\mathrm{HSC}^{\mathrm{m} / \mathrm{m}}$ relative to $\mathrm{HSC}^{+/+}$(Figure $3 \mathrm{~F}$ ). Unexpectedly, $\mathrm{HSC}^{\mathrm{m} /+}$ also showed a marked reduction compared with $\mathrm{HSC}^{+/+}$. These findings are in sharp contrast to our previously published results that showed the higher reconstitutive potential of $\mathrm{HSC}^{-/-}$ and $\mathrm{HSC}^{+/-}$compared with $\mathrm{HSC}^{+/+}(16)$.

The low bone marrow reconstitutive potential of $\mathrm{HSC}^{\mathrm{m} / \mathrm{m}}$ and $\mathrm{HSC}^{\mathrm{m} /+}$ might be caused by an increased likelihood of self-renewal rather than differentiation by persistent $\mathrm{c}$-Kit on the cell surface due to low endocytosis. To test this possibility, we analyzed the bone marrow of recipient mice (Ly5.1) 3 months after HSC (Ly5.2) transplantation. Very low ratios of LT-HSC ${ }^{\mathrm{m} / \mathrm{m}}$, with a considerable reduction of $\mathrm{LT}^{-\mathrm{HSC}^{\mathrm{m} /+}}$, were observed (Figure $3 \mathrm{G}$ ). The ratios of Ly5.2 cells expressing Samd9 $\mathrm{L}^{\mathrm{D} 764 \mathrm{~N}}$ were then partially recovered in ST-HSC and MPP, indicating that LT-HSCs expressing Samd9 $\mathrm{L}^{\mathrm{D} 764 \mathrm{~N}}$ were overwhelmed by $\mathrm{HSC}^{+/+}$in a competitive bone marrow environment.

In summary, Samd9 ${ }^{\mathrm{D} 764 \mathrm{~N}}$ reduces the surface receptor endocytosis of TfR and c-Kit in hematopoietic cells, causing anemia in mice $^{\mathrm{m} / \mathrm{m}}$. Although mice $\mathrm{m}^{\mathrm{m}+}$ showed normal peripheral blood and bone marrow indices, $\mathrm{HSPC}^{\mathrm{m} /+}$ showed cryptic low performance, such as more profound anemia induced by IFN and lower bone marrow reconstitutive potential.

Reduction of EGFR expression in testis ${ }^{m / m}$ and kidney ${ }^{m / m}$. A representative testis from a 6 -week-old mouse $\mathrm{e}^{\mathrm{m} / \mathrm{m}}$ showed well-developed seminiferous tubules (Figure 4A). However, interstitial spaces contained few acidophilic Leydig cells (LCs), which caused low serum testosterone (Figure 4B). A 14-week-old mouse tes- tis ${ }^{\mathrm{m} / \mathrm{m}}$ showed severe atrophy (Figure $4 \mathrm{~A}$ ). Immunohistochemistry of paraffin-embedded sections (IHC-p) revealed high Samd9L expression in LCs, consistent with a previous report describing high Samd9 expression in human LCs (4). We found high expression of EGFR in $\mathrm{LC}^{-/-}$as well as other cells in testis ${ }^{-/}$and low expression in $\mathrm{LC}^{\mathrm{m} / \mathrm{m}}$ (Figure $4 \mathrm{C}$ ).

A 6-week-old kidney ${ }^{\mathrm{m} / \mathrm{m}}$ showed apparently normal architecture (Figure 4D). Enlarged Bowman's capsules and proximal renal tubules were evident by 12 weeks, with large cysts destroying the renal architecture by 25 weeks. IHC-p revealed abundant expression of Samd9L in the kidney ${ }^{+/+}$, with the highest expression found in renal tubular epithelial cells (RTEs) of the outer cortical region (Figure 4E). In addition, marginal Samd9L ${ }^{\mathrm{D} 764 \mathrm{~N}}$ expression in the kidney ${ }^{\mathrm{m} /-}$ explains the lack of phenotype in mice ${ }^{\mathrm{m} /-}$ and mice ${ }^{\mathrm{m} /+}$.

EGFR expression was highest in RTE of the kidney ${ }^{+/+}$in the subcapsular layer (Figure 4F), which also expressed abundant Samd9L (Figure 4E). However, EGFR expression was further enhanced in $\mathrm{kidney}^{-/}$and suppressed in kidney ${ }^{\mathrm{m} / \mathrm{m}}$, suggesting that Samd9L downregulates EGFR expression. This somewhat paradoxical observation may be understood if Samd9L functions as a "limiter" of receptor expression levels.

Negative regulation of internalization of receptors by Samd9L and its mutant. To elucidate mechanisms of EGFR downregulation by Samd9L ${ }^{\mathrm{D} 764 \mathrm{~N}}$, we analyzed immortalized lung fibroblasts (LFs) established from mice ${ }^{+/+}$, mice $^{-/-}$, or mice m $^{\mathrm{m} / \mathrm{m}}$ that expressed Samd9L (in $\mathrm{LF}^{+/+}$and $\mathrm{LF}^{\mathrm{m} / \mathrm{m}}$ ) and EGFR at high levels (Figure $5 \mathrm{~A}$ ). Protein expression levels of Samd9L in $\mathrm{LF}^{\mathrm{m} / \mathrm{m}}$ relative to $\mathrm{LF}^{+/+}$ were lower $(0.32 \pm 0.08)$ compared with mRNA expression levels of Samd9L in $\mathrm{LF}^{\mathrm{m} / \mathrm{m}}$ relative to $\mathrm{LF}^{+/+}(0.73 \pm 0.07$, monitored by real-time quantitative PCR), suggesting the unstable nature of Samd9L $\mathrm{L}^{\mathrm{D} 764 \mathrm{~N}}$. Intriguingly, when LFs were cultured in serum/cytokine-free medium, surface EGFR expression levels of $L F^{\mathrm{m} / \mathrm{m}}$ were low compared with $\mathrm{LF}^{+/+}$or $\mathrm{LF}^{-/-}$(Figure 5B). In addition, Akt phosphorylation after EGF stimulation in $\mathrm{LF}^{\mathrm{m} / \mathrm{m}}$ was for a shorter period of time than in $\mathrm{LF}^{+/+}$(Figure $5 \mathrm{C}$ ). In contrast, $\mathrm{LF}^{-/-}$exhibited longer activation, in agreement with our previously published results using PDGF (16). Thus, the regulation of EGFR metabolism and signaling was preserved in these immortalized LFs, at least in part, although LFs grew in a cytokine-independent manner.

When $\mathrm{LF}^{+/+}$or $\mathrm{LF}^{-/-}$maintained in serum/cytokine-free medium were stimulated with EGF, EGFR localization was unaltered after 2 minutes (Figure 5D); however, puncta representing EGFR on early endosomes were detected for more than 30 minutes. In contrast, surface EGFR signals in $\mathrm{LF}^{\mathrm{m} / \mathrm{m}}$ were substantially reduced within 2 minutes, with puncta barely detectable within 10 minutes, suggesting rapid endocytosis of ligand-bound EGFR and degradation in lysosomes. We then applied SHIP analysis to LFs cultured without serum/cytokines to measure steady-state and ligand-independent EGFR internalization rates. $\mathrm{LF}^{+/+}$and $\mathrm{LF}^{-}$ ${ }^{1}$ showed a roughly $30 \%$ internalization rate in 5 minutes (Figure $5 \mathrm{E}$ ), much slower than ligand-bound EGFR endocytosis (almost $100 \%$ at 5 minutes, Figure 5D). Internalization of ligand-unbound EGFR in $\mathrm{LF}^{\mathrm{m} / \mathrm{m}}$ was faster than in $\mathrm{LF}^{+/+}$or $\mathrm{LF}^{-/-}$(Figure $5 \mathrm{E}$ ).

Ship2 translocation induced by Samd $9 L^{D 764 N}$. We tried to identify factors involved in the Samd $9 \mathrm{~L}^{\mathrm{D} 764 \mathrm{~N}}$-mediated upregulation of EGFR endocytosis by searching for proteins with altered expression or intracellular localization in $\mathrm{LF}^{\mathrm{m} / \mathrm{m}}$. We focused on $\mathrm{SH} 2$-contain- 
A

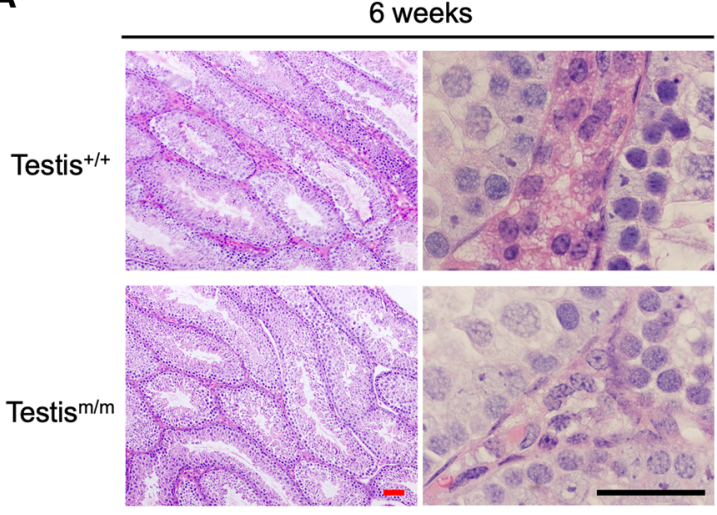

C

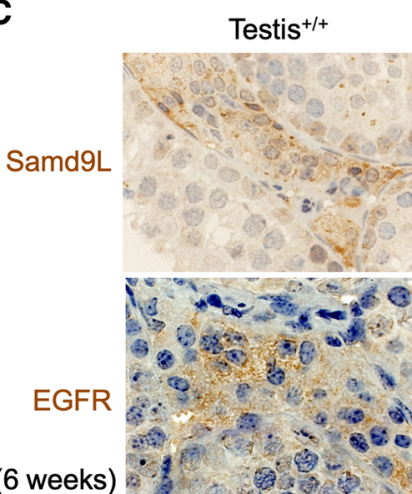

(6 weeks)

E

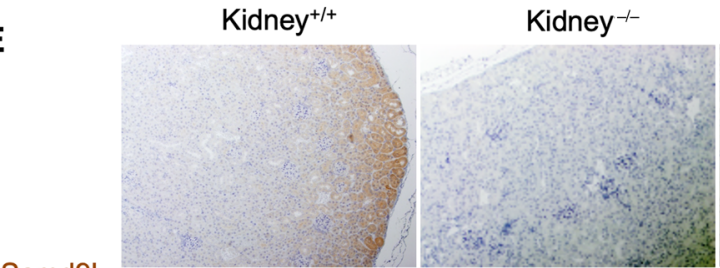

Samd9L
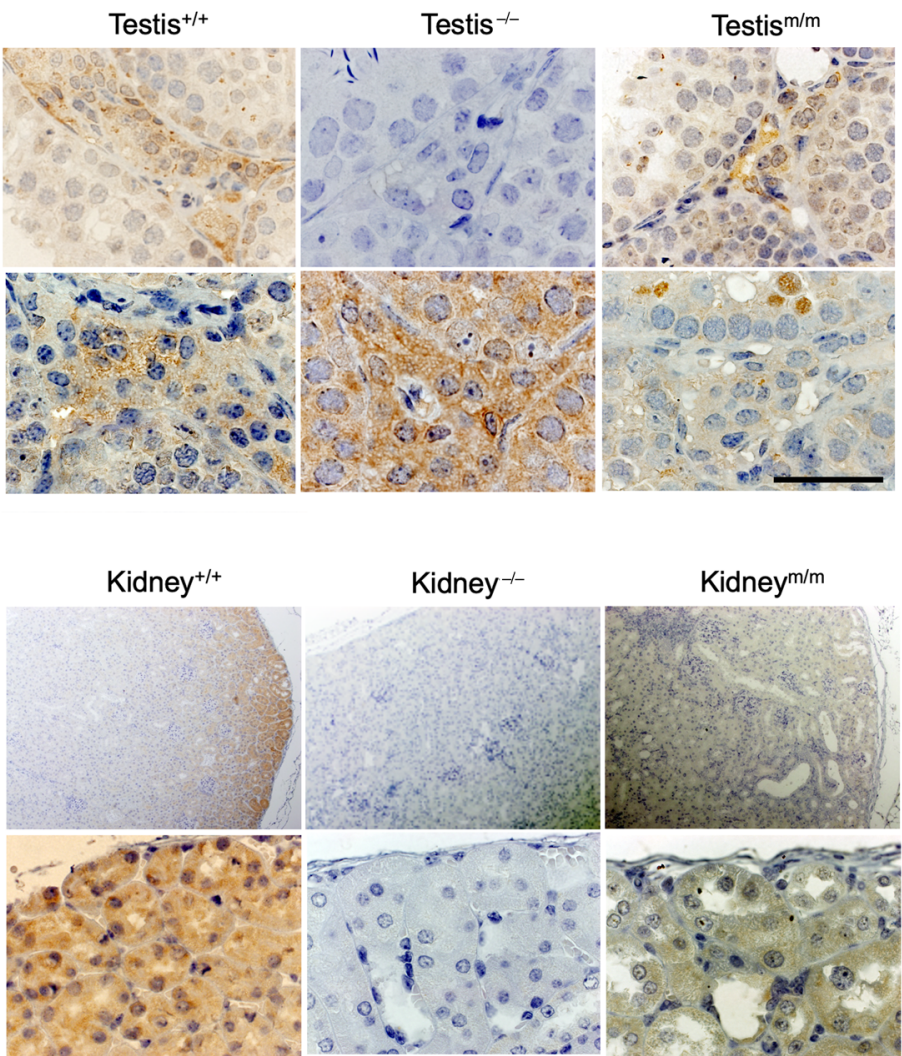

B

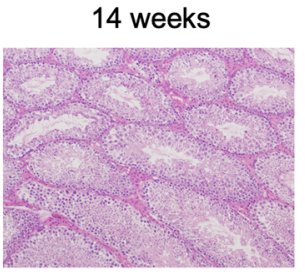

D

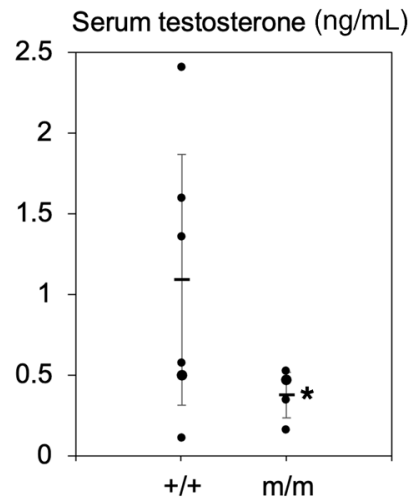

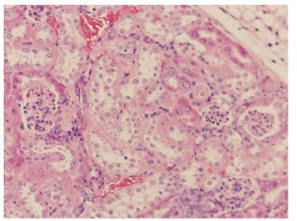
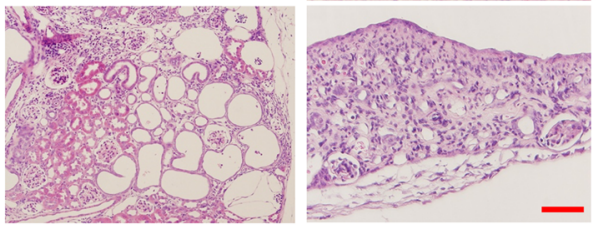

$\mathbf{F}$

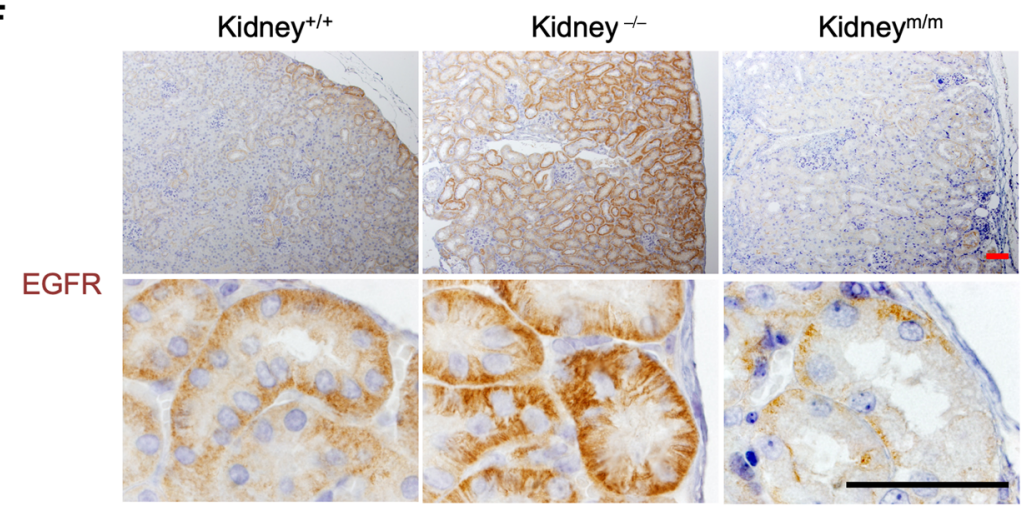

Kidney ${ }^{m / m}$

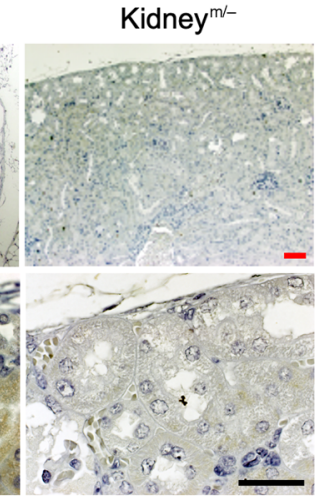

Figure 4. Reduced expression of EGFR in the testis $\mathrm{m} / \mathrm{m}$ and kidney ${ }^{\mathrm{m} / \mathrm{m}}$. (A and $\left.\mathbf{D}\right)$ H\&E staining of testis (A) or kidney (D). Age and genotype are indicated in the figures. (B) Serum testosterone concentration of 14 -week-old mice $\mathrm{e}^{+/+}(n=6)$ or mice $\mathrm{m}^{/ / m}(n=4)$ at 3:00 pm, the peak time of the circadian rhythm (55). Horizontal lines indicate the mean, vertical the SD. ${ }^{*} P<0.05$, 2-sided Student's $t$ test. (C and E-F) IHC-p stains of testis (C) or kidney (E and $\mathbf{F}$ ) from 6-weekold mice using antibodies indicated on the left with hematoxylin counterstaining. Scale bars: $20 \mu \mathrm{m}$ (red); $50 \mu \mathrm{m}$ (black). 
A
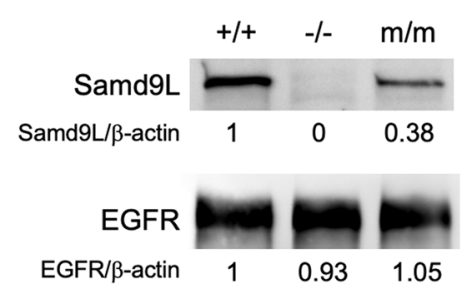

$\beta$-actin

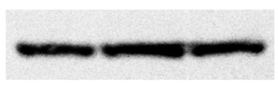

B

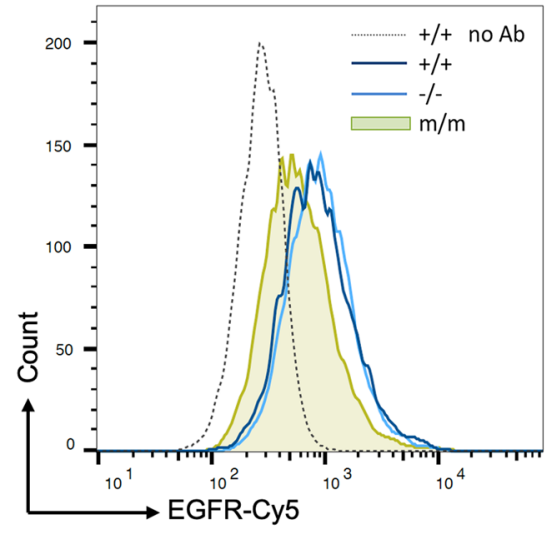

C

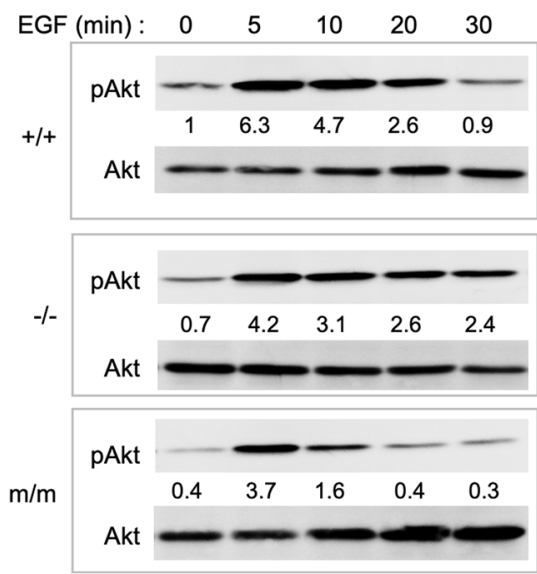

D
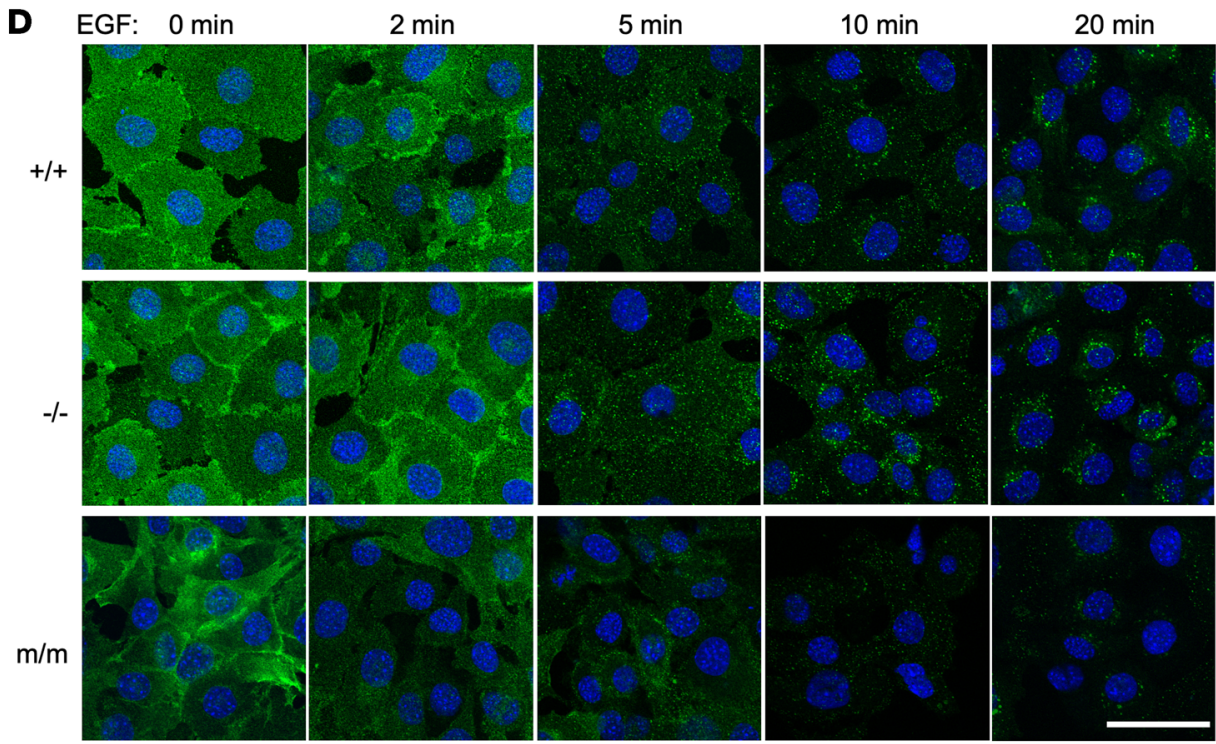

E

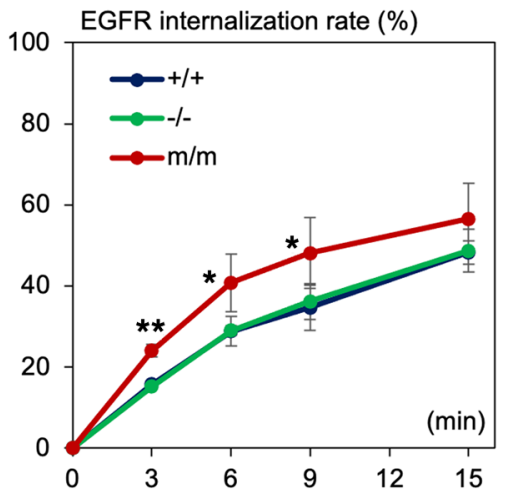

Figure 5. Rapid metabolism of EGFR in immortalized LF ${ }^{\mathrm{m} / \mathrm{m}}$. (A) Immunoblot analysis of LF extracts using Samd9L (top), EGFR (middle), or $\beta$-actin (bottom) antibodies. Samd9L genotypes are indicated above. The relative expression ratios of Samd9L or EGFR protein to $\beta$-actin are indicated. (B) Representative FCM histogram (of 3 independent experiments) of surface EGFR expression of LFs. (C and D) LFs were cultured in EGF-containing (50 ng/ $\mathrm{mL}$ ) medium for the indicated periods. Immunoblot detection using the antibodies indicated at left. The relative expression ratio of phosphorylated Akt (pAkt) to total Akt are indicated between panels (C). IF staining using EGFR antibody. Nuclei were stained with DAPI. Scale bar: $50 \mu \mathrm{m}$ (D). Representative results of 3 independent experiments. (E) SHIP analysis measuring the internalization of EGFR in LFs cultured in serum/cytokine-free medium. Means are plotted, and error bars show SD. ${ }^{*} P<0.05 ;{ }^{*} P<0.01$, Tukey's test.

ing $5^{\prime}$ inositol phosphatase 2 (Ship2), which catalyzes the conversion of PI-3,4,5-triphosphate to PI-3,4-bisphosphate in order to promote endocytosis (36). Previous reports have demonstrated Ship2 translocates from the perinuclear region to the periphery of cells upon serum or cytokine stimulation $(37,38)$. This was also shown in $\mathrm{LF}^{+/}$. The number of cells showing perinuclear Ship2 localization (defined as described in the legend for Supplemental Figure 3) decreased, whereas cells showing diffuse Ship2 localization increased within 2 minutes after EGF stimulation (Figure 6, A and B). Whereas this translocation was delayed in $\mathrm{LF}^{-/}, \mathrm{LF}^{\mathrm{m} / \mathrm{m}}$ showed diffuse Ship2 localization in the absence of serum/cytokines (Figure $6, \mathrm{~A}$ and $\mathrm{B}$ ). In addition, $\mathrm{RTE}^{+/+}$primary cultures in serum/ cytokine-free medium showed a perinuclear localization of Ship2 with few fluorescent signals outside stress fibers and lamellipodia (Figure 6C); EGF stimulation led to the translocation of Ship2 to the surface of $\mathrm{RTE}^{+/+}$within 2 minutes (Figure 6D). In contrast, a large amount of Ship2 localized in the lamellipodia of $\mathrm{RTE}^{\mathrm{m} / \mathrm{m}}$ in the absence or presence of EGF (Figure 6, E and F).

We then observed Ship2 localization in polarized RTE. IHC-p staining of the kidney showed most Ship2 proteins were present in the apical region (brush border) of $\mathrm{RTE}^{+/+}$and $\mathrm{RTE}^{-/}$, overlapping with dense periodic acid-Schiff (PAS) staining (Figure $6 \mathrm{G}$ ), and only faint striated staining was seen in the basal region, where EGFR existed (Figure 4F). In contrast, dense staining was observed in the basal region of $\mathrm{RTE}^{\mathrm{m} / \mathrm{m}}$, highlighting the altered distribution of Ship2. These findings were supported by IF: although Ship2 protein localized to the brush border showed faint staining, probably due to differences in the fixation procedure (Figure 6H), markedly enhanced Ship2 signals near transverse basal actin bundles were evident in kidney $\mathrm{y}^{\mathrm{m} / \mathrm{m}}$. 
A
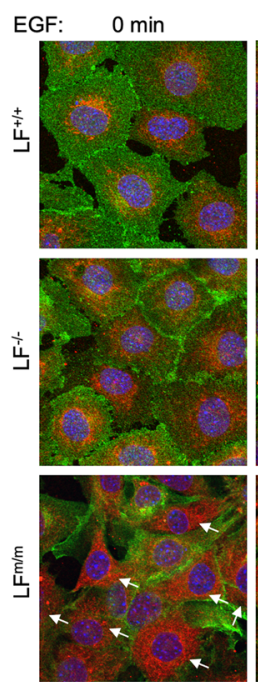

SHIP2 (Cy3) EGFR (af488) DAP

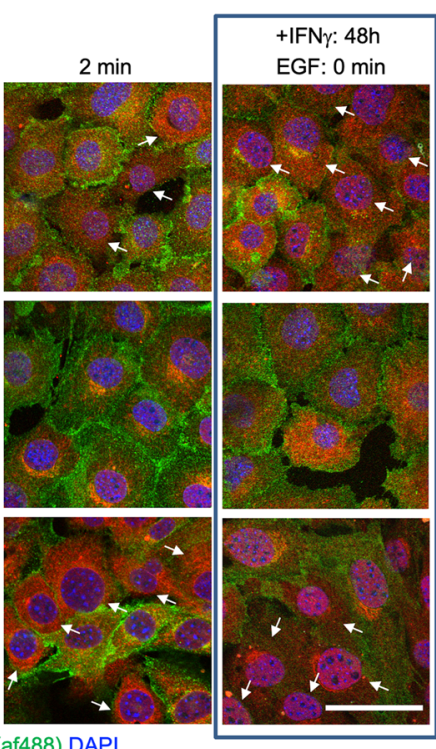

Kidney-
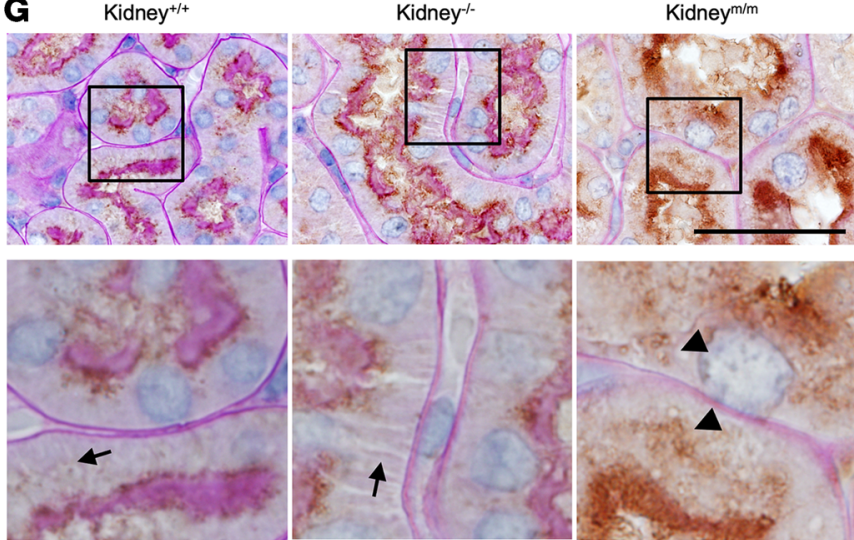

SHIP2 PAS

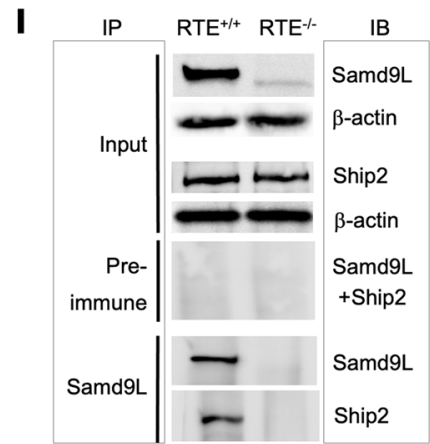

B \% Cells with diffuse Ship2
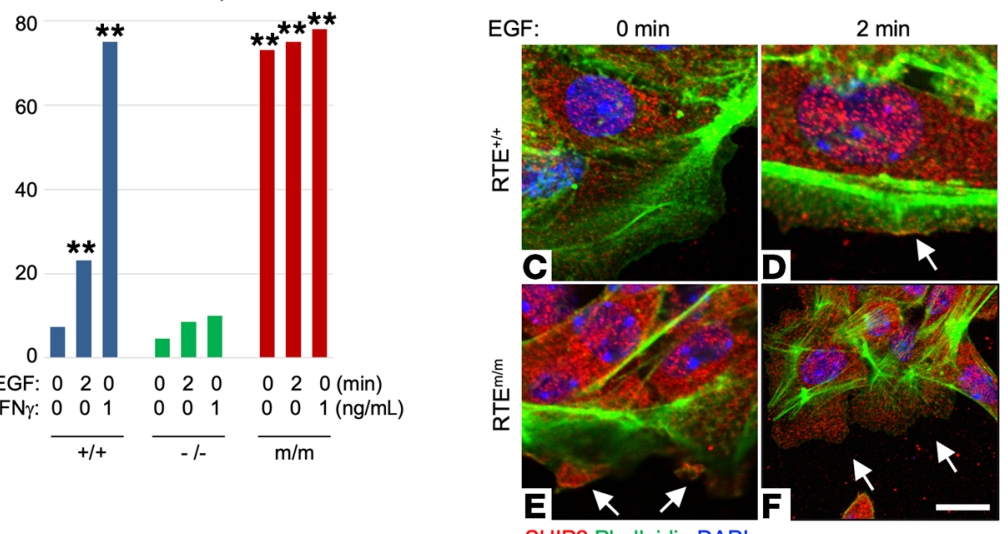

SHIP2 Phalloidin DAPI
H

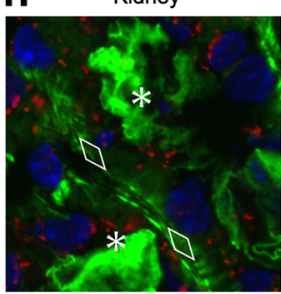

SHIP2 Phalloidin DAPI
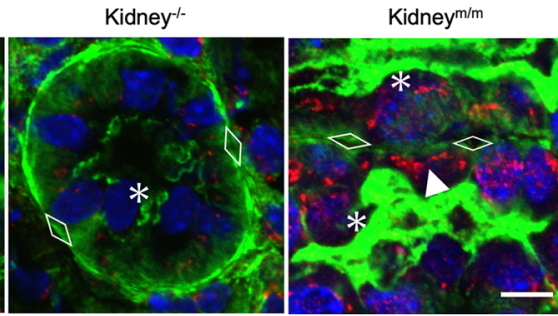

$\mathbf{J}$

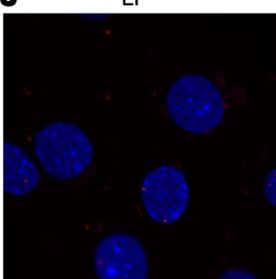

$\mathrm{LF}^{+/+}$

$\mathrm{LF}^{\mathrm{m} / \mathrm{m}}$
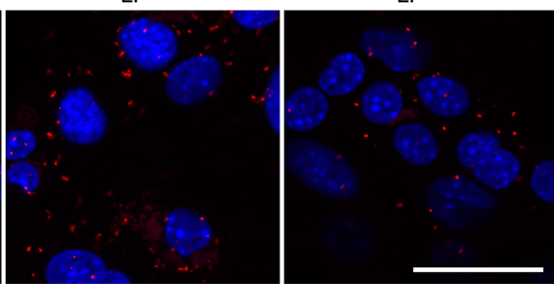

PLA signals (Samd9L-Ship2) DAP

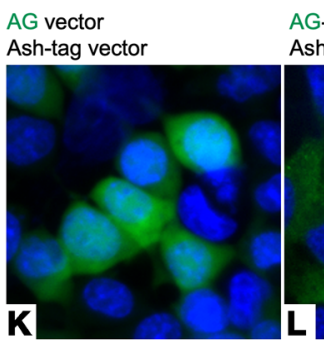

AG-Samd9L

Ash-tag vector

AG-Samd9L Ash-tag Ship2

Hoechst33342
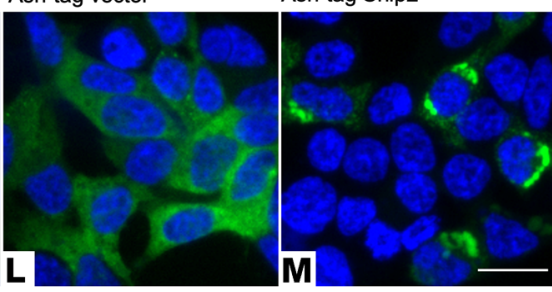

1

Figure 6. Samd9L ${ }^{0764 \mathrm{~N}}$ alters intracellular localization of Ship2. (A-F) LF (A) or primary cultures of RTE from 1-week-old mice (C-F) maintained in serum/ cytokine-free medium were cultured in EGF $(50 \mathrm{ng} / \mathrm{mL})$ or IFN- $\gamma$-containing $(1 \mathrm{ng} / \mathrm{mL})$ medium. Cells were stained with the antibodies indicated and phalloidin for F-actin. Arrows indicate cells showing diffuse Ship2 localization (A) and lamellipodia in (C-F). Ratios of cells exhibiting diffuse Ship2 localization. Two hundred cells were counted. ${ }^{*} P<0.01, \chi^{2}$ test (B). (G and $\left.\mathbf{H}\right)$ IHC-p stains using Ship2 antibody with PAS staining and hematoxylin counterstaining (C) and IF of frozen sections (H) of 6-week-old mouse kidneys. Insets (upper) are further magnified; arrows highlight the striated localization of Ship2 and arrowheads dense Ship2 signals in the basal region. Asterisks indicate brush border, and diamonds indicate basal actin bundles. (I) Immunoblots of cell extracts from RTEs (input). Immunoblots of immunoprecipitated products by preimmune serum or the Samd9L antibody. Antibodies using immunoblot analysis are shown at the right. Data are representative of 3 independent experiments. (J) D-PLA assay of LF using Samd9L (A6m) and Ship2 antibodies as primary antibodies. (K-M) Fluoppi assay using $293 \mathrm{~T}$ cells. Images of AG and Hoechst 33342-stained nuclei (blue) were merged. Nuclei were stained with DAPI (A, C-F, H, and J) or Hoechst 33342 (K-M). Scale bars: $50 \mu \mathrm{m}$ (A, C-H, and J); $20 \mu \mathrm{m}$ (K-M). 
A

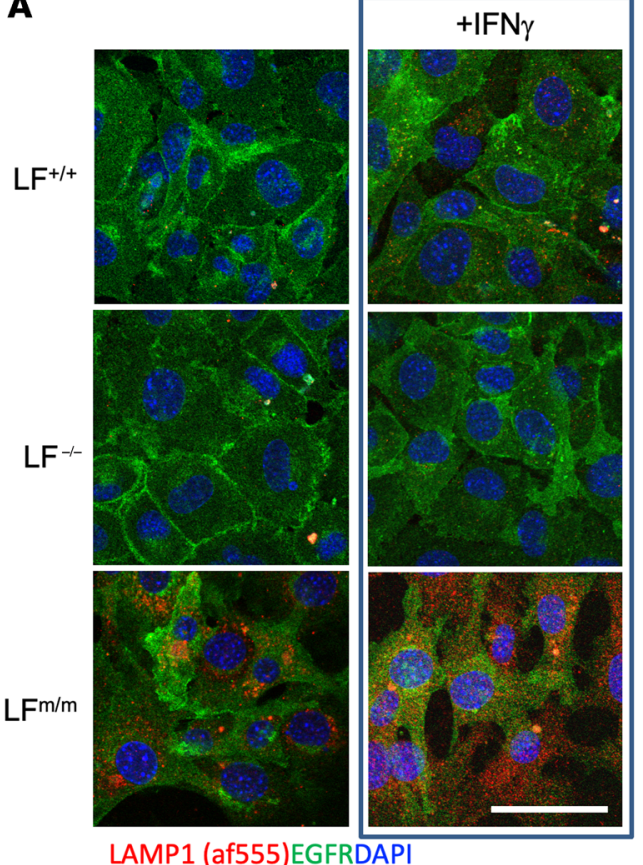

E

Positive dots/nucleus

60

40

20
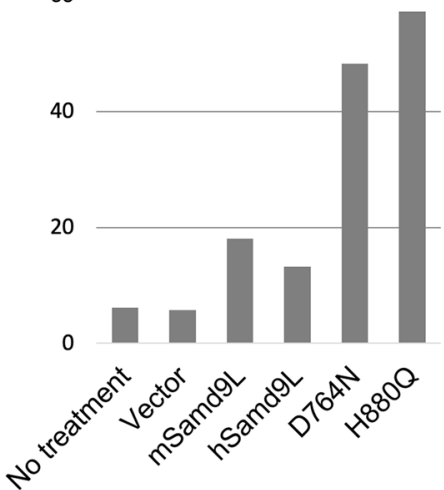

G

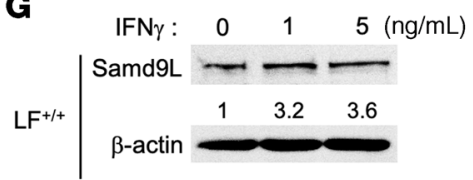

$\mathrm{LF}^{\mathrm{m} / \mathrm{m}} \mid \begin{aligned} & \text { Samd9L } \\ & \beta \text {-actin }\end{aligned}$
B

$\%$ of areas red $>$ green

40

30

20

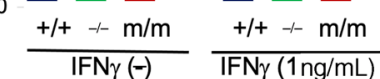

C

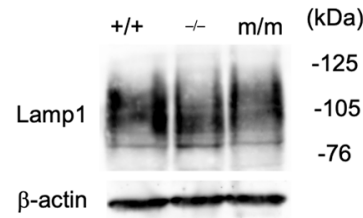

$\mathbf{F}$
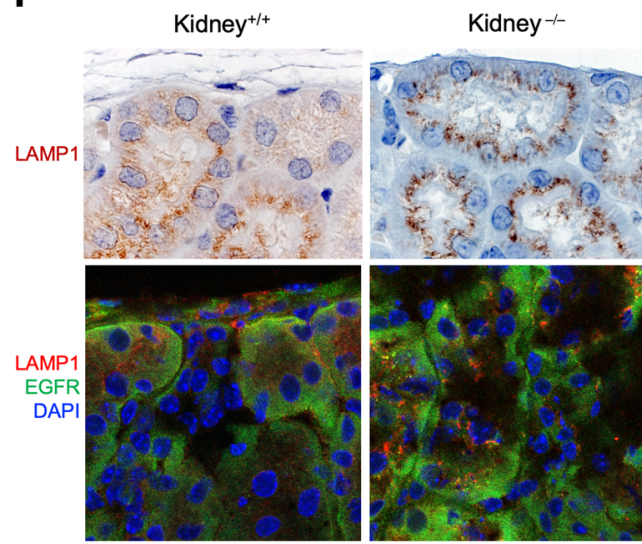

Kidney ${ }^{m / m}$
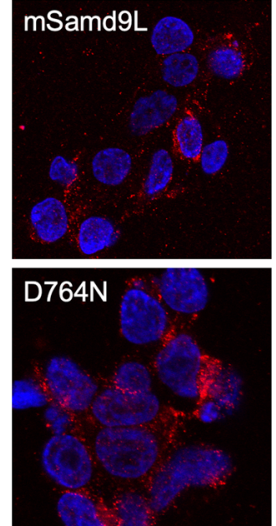

Lamp1 DAP

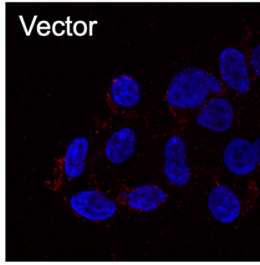

hSamd9L

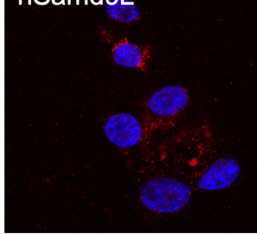

$\mathrm{H} 880 \mathrm{Q}$
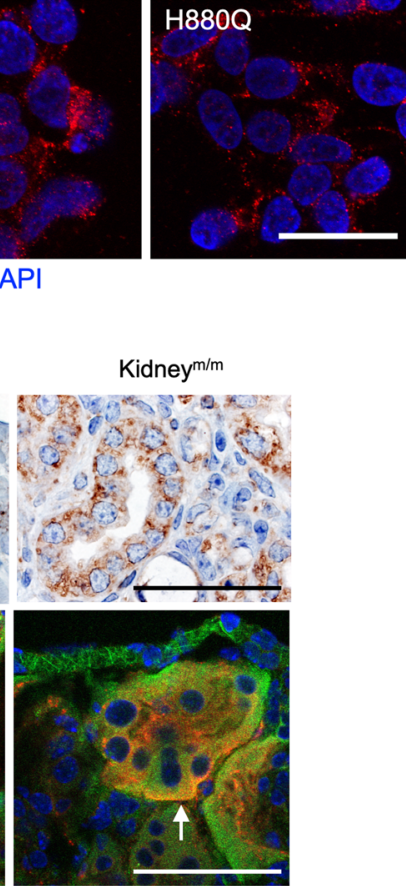

H

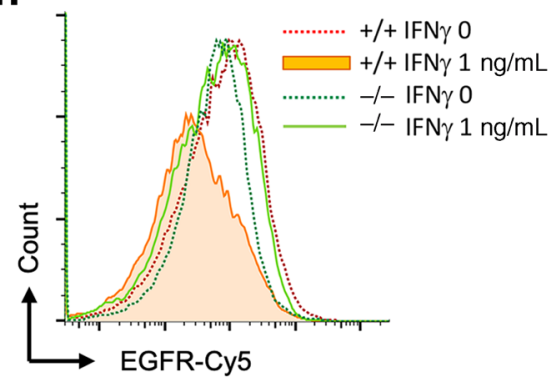

Figure 7. Samd9L ${ }^{0764 \mathrm{~N}}$ translocates Ship2 and activates lysosomes under the control of IFN. (A and B) LFs cultured in serum/cytokine-free medium (left panels) or medium containing IFN- $\gamma(1 \mathrm{ng} / \mathrm{mL})$ were stained with Lamp1 and EGFR antibodies (A). Quantification of areas of Lamp1 signals (red) greater than ECFR (green) using the method described in the legend of Supplemental Figure 3 (B). (C) Immunoblot detection of LF extracts using antibodies indicated at left. Representative data of 2 experiments. ( $\mathbf{D}$ and $\mathbf{E}) 293$ cells were transiently transfected with a pCMV3 expression vector containing cDNA of SamdgL as indicated. Cells were stained with a Lamp1 antibody (D). Number of pixels positive for red signals determined by Imagel software divided by the number of nuclei are shown (E). (F) IHC-p with hematoxylin counterstaining (upper) and IHC-f (lower) of 6-week-old mouse kidney using antibodies listed at left. The overlap of EGFR and Lamp1 signals is shown by an arrow. (G) $\mathrm{LF}^{+/+}$or LF ${ }^{\mathrm{m} / \mathrm{m}}$ were cultured with IFN- $\gamma$ at the concentrations indicated above for 48 hours. Extracts were subjected to immunoblot analysis using antibodies indicated at left. Relative expression ratios of Samd9L to $\beta$-actin are indicated between the 2 panels. Representative data of 3 independent experiments. (H) LFs were cultured with IFN- $\gamma(1$ and $5 \mathrm{ng} / \mathrm{mL}$ ) for 48 hours. Representative FCM histogram (of 3 independent experiments) of surface EGFR expression. Nuclei were stained with DAPI. Scale bars: $50 \mu \mathrm{m}$. 
Immunoblot analysis of immunoprecipitated products of RTE extracts by Samd9L antibody revealed the association of Ship2 with Samd9L (Figure 6I). Although colocalization of these 2 proteins was not clearly shown by conventional IF staining (data not shown), a highly sensitive Duolink in situ proximity ligation assay (D-PLA) revealed interactions between endogenous Ship2 and Samd9L or Samd9 $\mathrm{L}^{\mathrm{D} 764 \mathrm{~N}}$ in $\mathrm{LF}^{+/+}$or $\mathrm{LF}^{\mathrm{m} / \mathrm{m}}$, respectively (Figure 6J). We also performed fluorescent-based technology detecting protein-protein interactions (Fluoppi) (39) in living $293 \mathrm{~T}$ cells. In this assay, an Azami-green (AG) protein showed a diffuse distribution, when no binding partner tagged by an assembly helper (Ash) was coexpressed (Figure 6K), as shown in negative control cells that expressed AG vectors and an Ash-tag vector. Transient expression of a AG-hSamd9L fusion protein also yielded diffuse green fluorescence in the cytoplasm when the Ash-tag vector was coexpressed (Figure 6L). By the coexpression of AG-hSamd9L fusion and Ash-tagged-Ship2 protein, puncta appeared in the perinuclear region where Ship2 localized (Figure 6M), showing interaction between hSamd9L and Ship2 in this experimental system.

Lysosome activation by Samd $9 L^{D 764 N}$ and IFN. The rapid disappearance of EGFR signals in $\mathrm{LF}^{\mathrm{m} / \mathrm{m}}$ (Figure 5D) suggested lysosome activation. When cultured in serum/cytokine-free medium, immunostaining of lysosomal-associated membrane protein 1 (Lamp1) yielded a few Lamp1 signals in $\mathrm{LF}^{+/+}$or $\mathrm{LF}^{-}$ /-, but markedly enhanced signals in $\mathrm{LF}^{\mathrm{m} / \mathrm{m}}$ (Figure 7, A and B). Because immunoblot analysis showed that total Lamp1 protein levels remained relatively unchanged across LF cell lines (Figure 7C; Lamp1 bands look smeared because of heavy glycosylation), enhanced signals were likely caused by Lamp1 concentrating in lysosomes. In addition, the forced expression of Samd9 $\mathrm{L}^{\mathrm{D} 764 \mathrm{~N}}$ and human Samd9 $\mathrm{L}^{\mathrm{H} 880 \mathrm{Q}}$, a causative mutation of AP syndrome (5), in HEK293 cells markedly increased Lamp1 signals (Figure 7, D and E).

Kidney IHC-p revealed diffusely distributed Lamp1 with dense staining in the apical region of $\mathrm{RTE}^{+/+}$, while signals were strictly limited to the apical region of $\mathrm{RTE}^{-/-}$(Figure 7F). In contrast, dense signals were observed in the basal region of $\mathrm{RTE}^{\mathrm{m} / \mathrm{m}}$. IHC for frozen sections (IHC-f) confirmed these results (Figure $7 F$ ) and showed a notable overlap of EGFR with Lamp1 signals in the basal region of $\mathrm{RTE}^{\mathrm{m} / \mathrm{m}}$.

Because Samd9/9L are IFN-responsive genes (8-10), Ship2 translocation and lysosome activation may be IFN functions. To test this, we cultured $\mathrm{LF}^{+/+}$and $\mathrm{LF}^{\mathrm{m} / \mathrm{m}}$ in medium containing IFN- $\gamma$ for 48 hours. Normal and mutated Samd9L expression were enhanced in $\mathrm{LF}^{+/+}$and $\mathrm{LF}^{\mathrm{m} / \mathrm{m}}$, respectively (Figure $7 \mathrm{G}$ ). In $\mathrm{LF}^{+/+}$, but not in $\mathrm{LF}^{-/-}$, the number of cells showing diffuse Ship2 localization increased (Figure 6, A and B). Mildly enhanced Lamp1 signals (Figure 7, A and B) and reduced surface EGFR expression (Figure $7 \mathrm{H}$ ) were observed in $\mathrm{LF}^{+/+}$. In $\mathrm{LF}^{\mathrm{m} / \mathrm{m}}$, the distribution of Ship2 (Figure 6, A and B) and surface EGFR expression (data not shown) were not altered significantly; however, markedly enhanced Lamp1 signals were observed (Figure 7, A and B). These data suggested a role for Samd9L as a downstream regulator of IFN- $\gamma$ in defense mechanisms against viruses. The constitutive upregulation by $\mathrm{g} / \mathrm{f}$ mutations might impair organs that express Samd9L at high levels.

\section{Discussion}

The presence of Samd9/9L mutations identified in patients with multiple organ degeneration suggests functions gained by such mutations impair the fundamental systems for cell growth, survival, and differentiation. A clue to this notion was found in the similarities of mice $^{\mathrm{m} / \mathrm{m}}$ to Picalm-deficient mice. Both mouse groups develop a rare type of anemia associated with erythroblasts expressing high-surface TfR due to the reduction of Tf-TfR internalization (Figure $2 \mathrm{H})(31)$, indicating that Samd9 $\mathrm{L}^{\mathrm{D} 764 \mathrm{~N}}$ impairs CME. In addition, c-Kit was also slowly internalized in $\mathrm{HSPC}^{\mathrm{m} / \mathrm{m}}$ (Figure 3E).

In contrast to hematopoietic cells, the endocytosis of either ligand-bound or -unbound EGFR is upregulated by Samd9L ${ }^{\mathrm{D} 764 \mathrm{~N}}$ in $\mathrm{LF}^{\mathrm{m} / \mathrm{m}}$ (Figure 5, D and E) through the translocation of Ship2 to the cell periphery (Figure 6, A and B). This discrepancy may be caused by the expression of another PI-3,4,5-triphosphate phosphatase, Ship1, in hematopoietic cells. Because hematological disturbances occur in Ship1- but not Ship2-deficient mice (40-42), Ship2 is unlikely to play a dominant role in hematopoietic cells. The 2 phosphatases differ in the presence of a sterile alpha motif (SAM) domain in the C-terminal region of Ship2, but share common motifs and domains elsewhere. Because the SAM domain is a protein interaction module present in a wide variety of proteins involved in many biological processes, we determined whether Samd9/9L binds to Ship2 through their SAM domains. The contribution of SAM domains to the interaction was ambiguously demonstrated (data not shown), meaning detailed molecular mechanisms remain to be clarified.

Low EGFR expression in LCs from mice $\mathrm{m}^{\mathrm{m} / \mathrm{m}}$ (Figure 4C) would impair LC proliferation and steroidogenesis (43) or the development of stem cells and progenitors of LCs during puberty (44), although the contribution of other growth factors, such as PDGF or fibroblast growth factors, has been emphasized for the development and function of LCs $(45,46)$. In addition, a few papers have reported the contribution of EGFR-derived signals to maintenance kidney integrity (47), since EGFR-deficient mice show pre- or perinatal fatalities. It is not surprising that various growth factors cooperatively contribute to the integrity of organs. The low expression of EGFR is most likely a combined effect of enhanced endocytosis and lysosomal activity that is a common regulatory mechanism for receptor tyrosine kinases. Thus, it is conceivable that reduced surface receptors for EGF and other growth factors would impair multiple organs of mice $\mathrm{m}^{\mathrm{m}}$ and/or patients with Samd9/9L syndrome that express Samd9L at high levels.

In contrast to enhanced EGFR endocytosis in $\mathrm{LF}^{\mathrm{m} / \mathrm{m}}, \mathrm{HSPC}^{\mathrm{m} / \mathrm{m}}$ showed reduced c-Kit endocytosis and a low response to SCF (Figure 3E). This might induce high-surface c-Kit, like high TfR expression in erythroblasts $\mathrm{m} / \mathrm{m}$ (Figure $2 \mathrm{~F}$ ). Unfortunately, it was technically difficult to measure surface expression levels of c-Kit in HSPC, because the c-Kit antibody itself is required to distinguish HSPC from various c-Kit-expressing cells with a wide variety of expression levels. In bone marrow, cells from different lineages and/or maturation stages that require the same cytokine(s) are located adjacent to each other. We recently demonstrated that, in a coculture of murine IL-3-dependent cells using membrane inserts permeable to IL-3 but that restricted cell transfer, cells with rapid IL-3R internalization/low surface IL-3R gained a growth advantage over cells with 
slower endocytosis/high surface receptors by "stealing" IL-3 from the latter (48). Thus, rapid internalization rather than surface receptor levels appears crucial in bone marrow.

Unlike patients with Samd9/9L syndrome, mice ${ }^{\mathrm{m} /+}$ after birth showed normal maturation and peripheral blood indices. In addition, the numbers and in vitro growth potential of $\mathrm{HSPC}^{\mathrm{m} /+}$ were not significantly different from those of $\mathrm{HSPC}^{+/+}$(Figure 3, A-E). We considered that this discrepancy between humans and mice was due to the relatively low expression levels of Samd9 $\mathrm{L}^{\mathrm{D} 764 \mathrm{~N}}$ in mice carrying this mutation, typically shown in the kidney (Figure 4E), which expresses Samd9L at the highest levels among mouse organs (28). Indeed, the induction of normal and mutated Samd9L by Poly(I:C) reduced the $\mathrm{Hb}$ concentration in mice $\mathrm{m}^{\mathrm{m} /+}$ more profoundly than in mice $^{+/+}$, whereas little reduction was observed in mice ${ }^{-/-}$(Figure 2C). An expression level-dependent symptom was also shown in mice $^{\mathrm{m} / \mathrm{m}}$, since Poly(I:C) i.p. injections caused a rapid deterioration of the systemic condition of mice $\mathrm{m}^{\mathrm{m} / \mathrm{m}}$ that resembles that of patients with Samd9/9L syndrome, who frequently experience such episodes after a viral infection $(3,4)$. In this regard, that specific pathogen-free mice have few chances of a viral infection may explain the relatively mild bone marrow findings of mice ${ }^{\mathrm{m} / \mathrm{m}}$ (normocellular bone marrow with isolated anemia and $\mathrm{B}$ lymphopenia) compared with humans.

The low bone marrow reconstitutive potential of $\mathrm{HSC}^{\mathrm{m} /+}$ (Figure 3F) appears to be inconsistent with the normal peripheral blood and bone marrow indices of mice ${ }^{\mathrm{m} /+}$. The elevation of IFN- $\gamma$ in the process of allogenic bone marrow transplantation in mice as well as in humans (reviewed in ref. 49) would be a cause of this discrepancy: $\mathrm{HSC}^{\mathrm{m} /+}$, as well as $\mathrm{HSC}^{\mathrm{m} / \mathrm{m}}$, with a reduced surface receptor internalization was overwhelmed by $\mathrm{HSC}^{+/+}$in bone marrow growth competition. We previously reported that the bone marrow-reconstitutive potential of $\mathrm{HSC}^{+/}$overcomes that of $\mathrm{HSC}^{+/+}(16)$. Thus, we consider that IFN- $\gamma$ induced by recurrent viral infection in patients with Samd9/9L syndromes not only worsens bone marrow failure, but also expands preexisting -7/ $\operatorname{del}(7 \mathrm{q})$ clone or clones that have lost mutated Samd9/9L genes.

This mouse model system provides a scenario for the pathogenesis of Samd9/9L syndrome, in which a mutated Samd9L causes multiple organ failure, yet the evidence for causal links between the associated findings was mostly indirect. To build a firm theory of Samd9/9L syndrome from this speculative proposed model, elucidation of the molecular mechanisms involved is crucial. Samd9 $\mathrm{L}^{\mathrm{D} 764 \mathrm{~N}}$ affects the internalization rate of surface receptors and enhances lysosomal activity. However, analysis of the Samd $9 L$-deficient mouse and its derived cells revealed the downregulation of the homotypic fusion of early endosomes, resulting in delays in degradation of PDGFR in lysosomes (16). A common molecular mechanism might be the Samd9/9L regulation of each of these 3 steps: endocytosis of receptors, homotypic fusion of endosomes, and lysosomal activation. An important direction in Samd9/9L syndrome research would be to generate a new mouse model that carries an artificial chromosome containing the human genome spanning whole Samd9 and Samd9L genes to diminish species differences due to the lack of the Samd9 gene in the mouse genome. Such studies will provide useful clues in answering unsolved questions, such as why so many g/f mutations exist throughout Samd9/9L and why some mutations cause nonhematological disorders while others do not.

\section{Methods}

Mouse experiments. The Samd9L ${ }^{\mathrm{D} 764 \mathrm{~N}}$ knockin mouse lines (mice $\mathrm{e}^{\mathrm{m} / \mathrm{m}}$ ) were created by the pronuclear injection of Cas9 protein (Thermo Fisher Scientific), synthetic transactivating CRISPR RNA (tracrRNA) (AAACAGCAUAGCAAGUUAAAAUAAGGCUAGUCCGUUAUCAACUUGAAAAAGUGGCACCGAGUCGGUGCU), CRISPR RNA (crRNA) (GCAACUGAUUUUGUAGAGAUGUUUUAGAGCUAUGCUGUUUUG; target sequence: GCAACTGATTTTGTAGAGAT), and an oligonucleotide repair template (ACTACGTTGGCGATGCATGTTCTCTGGGACTTAAAGCAGAAGTTTCGGTGTGCTGTCTTGAAAAACAAAGCAACTAAATTTTGTAGAGATTGGAGAACAAGTAAGCAAGCTAATGAGCTACAAGGCTACCAGCCACGAGGATTCATTCCC; underline indicates a base substitution that causes an amino acid replacement, D764N) (Fasmac) into C57BL6/N F2 fertilized oocytes, as previously described (27). Briefly, $30 \mathrm{ng} / \mu \mathrm{L}$ Cas 9 protein, $8.7 \mathrm{ng} / \mu \mathrm{L}$ Samd9L crRNA, $14.3 \mathrm{ng} / \mu \mathrm{L}$ tracrRNA, and $100 \mathrm{ng} / \mu \mathrm{L}$ oligonucleotides were mixed in TE buffer and incubated at $37^{\circ} \mathrm{C}$ for at least 10 minutes before the pronuclear injection of 1-cell stage zygotes. Once the embryos reached the 2-cell stage, they were transferred into the fallopian tubes of pseudopregnant females. Correctly mutated founder animals were identified by sequencing across the mutation site. A Samd9L ${ }^{\mathrm{D} 764 \mathrm{~N}}$ hemizygous male founder was able to breed. Female heterozygous offspring $\left(\right.$ mice $\left.^{\mathrm{m} /+}\right)$ were verified by sequencing or TaqMan SNP GenotypingAssay (Thermo Fisher Scientific) at 4 weeks of age and used for further breeding of the line. Samd $9 \mathrm{~L}$-deficient mice (mice ${ }^{-/-}$) were generated and maintained in our institute (16) and deposited to Riken BioResource Research Center (RBRC05498). C57BL/6N mice (Charles River Laboratories) and CD45.1 congenic mice (The Jackson Laboratory, stock 002014) were purchased. Polyinosinic-polycytidylic acid (catalog P1530; Sigma-Aldrich) was i.p. injected into 8-week-old male mice twice a week for 1 month at a dose of $300 \mu \mathrm{g}$. Blood samples were collected under anesthesia from the tail vein using heparinized hematocrit capillaries (catalog 2018-05; Hirschmann Laborgeraete). Peripheral blood cells were counted using an automated blood cell counter (PCE-310; ERMA Inc.). Peripheral blood chimerisms of recipient mice were analyzed as previously described (50). Serum iron (Nitroso-PSAP colorimetric method; catalog FEO2; Metallogenics) and Epo (enzyme-linked immunosorbent assay method; catalog KE00153; Proteintech Group) concentrations were measured using kits according to the manufacturers' instructions. Serum testosterone (time-resolved fluorescence immunoassay method) was measured by Cosmo Bio.

Bone marrow isolation and culture. Long bones were collected, and bone marrow cells were flushed out with PBS. The isolated cells were treated with RBC lysis buffer (catalog 00-4333-57; Thermo Fisher Scientific) for 5 minutes at room temperature (RT), washed twice, and then subjected to further analysis. To isolate the Lin $^{-}$cells, bone marrow cells were subjected to magnetic bead selection using a Lineage Cell Depletion Kit (catalog 130-090-858; Miltenyi Biotec) according to the manufacturer's instructions. Lin $^{-}$cells were cultured in IMDM-based primary culture medium with the following: $1 \%$ penicillin-streptomycin, $10 \mathrm{mM}$ HEPES (catalog 12440-053, 15140, 14190, respectively; Gibco, Thermo Fisher Scientific), $55 \mu \mathrm{M}$ 2-mercaptoethanol (catalog M7522; Sigma-Aldrich), and 10\% FBS. IMDM was supplemented with cytokines as follows: mouse SCF (mSCF; 100 $\mathrm{ng} / \mathrm{mL}$ ), human TPO (hTPO; $100 \mathrm{ng} / \mathrm{mL}$ ), mouse Fms-like tyrosine kinase 3 (mFlt3; $20 \mathrm{ng} / \mathrm{mL}$ ), and mouse IL-6 (mIL-6; $20 \mathrm{ng} / \mathrm{mL}$; catalog 300-18, 216-16, 250-03, and 250-31L, respectively; PeproTech) 
for 5 days at a final cell density of $2.5 \times 10^{5}$ cells $/ \mathrm{mL}$. The number of viable/dead cells present were counted by trypan blue dye exclusion test. For erythroid differentiation, purified Lin $^{-}$cells were cultured for 3 days at a final concentration of $1 \times 10^{5}$ cells $/ \mathrm{mL}$ in IMDM medium supplemented with $1 \% \mathrm{BSA}, 500 \mu \mathrm{g} / \mathrm{mL}$ holo-transferrin, $10 \mu \mathrm{g} /$ $\mathrm{mL}$ recombinant human insulin (catalog A3311, T0665, and I6634, respectively; Sigma-Aldrich), 2 mM L-glutamine (catalog 25030149; Gibco, Thermo Fisher Scientific), 2 U/mL Epo (catalog 100-64; PeproTech), and $15 \%$ FBS.

Flow cytometry. Erythrocytes were eliminated by incubating with erythrocyte lysis solution (catalog 555899; BD Bioscience). Cells were then stained with the relevant mixture of antibodies in PBS with $2 \%$ FBS (FACS buffer) for 20 minutes at $4^{\circ} \mathrm{C}$. Cells were pelleted by centrifugation, washed twice, and then resuspended in FACS buffer. Bone marrow and peripheral blood mononuclear cells were blocked with anti-mouse CD16/32 (catalog 553142; BD Biosciences - Pharmingen) in FACS buffer prior to antibody staining. The measurement and sorting of hematopoietic progenitors were performed using an antibody mixture against biotin-conjugated lineage markers, as follows: mixture of antibodies against Mac-1, Gr-1, B220, Ter119, CD3e (catalog 559971; BD Biosciences - Pharmingen); CD4 (catalog 13-0042-86; e-Biosciences); CD8a and PerCP-Cyanine (Cy) 5.5 conjugated streptavidin (catalog 553029 and 551419, respectively; BD Biosciences Pharmingen); along with CD34, Flt3, Sca-1, and c-Kit (catalog 560238, 553842 , 558162, 560185, respectively; BD Biosciences - Pharmingen). Differentiated bone marrow, spleen, and peripheral blood cells were stained with B220 and Gr-1 (catalog 103222 and 108416, respectively; BioLegend); CD90.2, CD45.2, CD45.1, CD11b, Ter119, and CD71 (catalog 553013, 558702, 553775, 553310, 557915, 561937, respectively; BD Biosciences - Pharmingen); and CD44 (catalog 17-0441-82; eBioscience). Propidium iodide (Pi; catalog 51-66211E; BD Biosciences - Pharmingen,) or 7-amino-actinomycin D (catalog 420404; BioLegend) was used to exclude dead cells. For the detection of an erythroid-lineage population, cells were stained using an antibody mixture against the biotin-conjugated lineage markers described above: CD5 (catalog 13-0051-85; eBioscience), Sca-I (catalog 557404; BD Biosciences - Pharmingen), IL-7 receptor (IL-7R $\alpha$; catalog 13-1271-81; eBioscience), and PerCP-Cy5.5 conjugated streptavidin along with CD150 (catalog 115909; BioLegend), and CD41, CD16/32, c-Kit, CD105 (catalog 561850, 560829, 554060, 562760, respectively; $\mathrm{BD}$ Biosciences - Pharmingen). Lineage-committed precursors were defined in a $\mathrm{Lin}^{-} \mathrm{Sca}-\mathrm{I}^{-} \mathrm{IL} 7 \mathrm{R} \alpha^{-} \mathrm{c}-\mathrm{Kit}^{+}$fraction as follows: megakaryocytic progenitors $(\mathrm{MkP}), \mathrm{CD} 150^{+} \mathrm{CD} 41^{+}$; granulocyte macrophage progenitors (GMP), CD $41^{-} \mathrm{CD} 16 / 32^{+}$; pre-CFU-E, CD $41^{-}$ $\mathrm{CD} 16 / 32^{-} \mathrm{CD}_{105}{ }^{+} \mathrm{CD} 150^{+}$; CFU-E, CD $41^{-} \mathrm{CD} 16 / 32^{-} \mathrm{CD} 105^{+} \mathrm{CD} 150^{-}$; pre-GM progenitor (PreGM), CD41-CD16/32-CD105-CD150; ${ }^{-}$and bipotent pre-Mk/erythroid progenitors (PreMegE), CD41-CD16/32

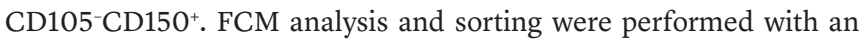
BD FACSCanto II, LSRFortessa instrument, FACSAria II (BD Biosciences). All FCM and FACS data were analyzed with FlowJo software (BD Biosciences).

Measurement of receptor internalization rates by SHIP analysis. SHIP analysis was performed according to the method described by others (34). Briefly, antibodies for receptors of interest were functionalized using a strained cyclooctyne and a kit (Click-IT succinimidyl ester dibenzocyclooctyne alkyne; Life Technologies) and then coupled with a fluorescent internalization probe (FIP) azide ( $5^{\prime}$ Cy5-TCAGTTCAG-
GACCCTCGGCT-N ${ }_{3}$ 3'; Integrated DNA Technologies). To measure the internalization of TfR, bone marrow cells were stained with FIPCy5 conjugated TfR antibody (catalog BD0175; BioCell Technology) or Tf (catalog T0665; Sigma-Aldrich) on ice for 30 minutes. Staining was followed by 2 washes and an incubation at $37^{\circ} \mathrm{C}, 5 \% \mathrm{CO}_{2}$ in DMEM to allow the internalization of ligand-bound receptors. Cells were then placed on ice at specific time points and were resuspended in wash buffer (5 mM EDTA, 2\% FBS in PBS) and then stained with anti-Ter119 antibody (catalog 557915; BD Biosciences - Pharmingen) for 30 minutes on ice to identify the cell population. To measure the internalization of c-Kit, whole bone marrow cells were cultured in the IMDM-based bone marrow primary cultured medium described above, supplemented with $100 \mathrm{ng} / \mathrm{mL} \mathrm{mSCF}, 100 \mathrm{ng} / \mathrm{mL}$ hTPO, 20 $\mathrm{ng} / \mathrm{mL} \mathrm{mIL-6}$, and $20 \mathrm{ng} / \mathrm{mL}$ mFlt3 ligand for 5 days. Lin ${ }^{-}$cells were isolated using a Lineage Cell Depletion Kit and cultured in IMDMbased bone marrow primary culture medium supplemented with 50 $\mathrm{ng} / \mathrm{mL} \mathrm{mSCF}$ and $10 \mathrm{ng} / \mathrm{mL}$ hTPO for 2 days. Cells were resuspended in DMEM containing 2\% FBS and blocked with anti-mouse CD16/32 for 5 minutes on ice, followed by staining with a FIP-Cy5-conjugated c-Kit antibody (BD0280; BioCell Technology) for 30 minutes. After washing twice, cells were incubated at $37^{\circ} \mathrm{C}, 5 \% \mathrm{CO}_{2}$ at specific time points. Cells were then stained with a biotin-conjugated lineage marker mixture (Mac-1, Gr-1, B220, Ter119, CD3ع) for 20 minutes, washed twice, and stained with phycoerythrin-Cy7-conjugated streptavidin (catalog 557598; BD Biosciences - Pharmingen) for 20 minutes. To measure internalization rates of EGFR in LF cultured with serum/ cytokine-free medium (described below), cells were dissociated with accutase (catalog AT104; Innovative Cell Technologies) and stained with FIP-Cy5-conjugated EGFR antibody (D1P9C, catalog 71655; Cell Signaling Technology) in DMEM supplemented with 10\% FBS at $4^{\circ} \mathrm{C}$ for 15 minutes. Cells were washed with DMEM supplemented with $10 \% \mathrm{FBS}$ and incubated at $37^{\circ} \mathrm{C}, 5 \% \mathrm{CO}_{2}$ at specific time points. All cells stained with FIP-Cy5-conjugated antibodies of interest were washed twice and resuspended in wash buffer containing $\mathrm{Pi}$, with or without $1 \mu \mathrm{M}$ quenching probe (QPc: $5^{\prime}$ AGCCGAGGGTCCTGAACTGA-BHQ2 3'; Integrated DNA Technologies), and subjected to FCM analysis. Data were analyzed with FlowJo software, and internalization rates were calculated using a formula described in a previously published paper (34).

Competitive reconstitution assay. Competitive reconstitution assays were performed as previously described (16). Briefly, we sorted LT-LSK cells, defined as $\mathrm{Lin}^{-}{ }^{-}-\mathrm{Kit}^{+} \mathrm{Sca}-{ }^{+}{ }^{+} \mathrm{Flt3}{ }^{-} \mathrm{CD} 34^{-}$, from $3 \mathrm{Sam}-$ $\mathrm{d} 9 \mathrm{~L}^{\mathrm{m} / \mathrm{m}}$ or Samd9L $\mathrm{L}^{+/+}$mice (Ly5.2 or CD45.2) and transplanted cells into lethally irradiated CD45.1 congenic mice (age 8 weeks) in competition with bone marrow mononuclear cells from CD45.1 mice. The reconstitution of donor cells was monitored by staining blood cells with antibodies against CD45.2 and CD45.1 using flow cytometry on a monthly basis.

Cells and cell culture. Primary culture of RTE was performed according to a previously described method (51). Briefly, kidneys were minced and transferred to collagenase solution $(150 \mathrm{U} / \mathrm{mL}$ collagenase [catalog 09353-04; Nacalai Tesque], $10 \mu \mathrm{g} / \mathrm{mL}$ soybean trypsin inhibitor [catalog 10109886001; Sigma-Aldrich] in PBS), followed by incubation at $37^{\circ} \mathrm{C}$ while gently rotating at $70 \mathrm{rpm}$ for 30 minutes. Following digestion, heat-inactivated horse serum was added at a 1:1 ratio, vortexed for 30 seconds, and allowed to stand for 1 minute. The supernatant containing the proximal tubules was 
removed and centrifuged for 7 minutes at $200 \mathrm{~g}$. Pellets were washed with DMEM, centrifuged again, resuspended in serum/cytokine free-medium (1:1 mixture of DMEM and Ham's F-12 medium supplemented with an insulin-transferrin-sodium selenite mixture; catalog 41405-045, Gibco, Thermo Fisher Scientific) and incubated at $37^{\circ} \mathrm{C}$ with $5 \% \mathrm{CO}_{2}$. Primary LFs were established as previously described (16), then immortalized with retrovirus expressing SV4O large T antigen. Briefly, PLAT-E cells (52) were transduced with a pBABE-SV40 large T vector (53) using a Lipofectamine 2000 transfection system (catalog 11668027; Thermo Fisher Scientific). Filtered virus supernatants were concentrated by centrifugation at $5,800 \mathrm{~g}$ for 16 hours at $4^{\circ} \mathrm{C}$ and suspended in culture medium. Primary LFs were treated with $4 \mathrm{mg} / \mathrm{mL}$ protamine. The following day, transduced cells underwent selection in $300 \mu \mathrm{g} / \mathrm{mL}$ G418 (catalog16513-26; Nacalai Tesque) for 1 week. Immortalized LFs and RTEs were maintained in serum/cytokine-free medium. Murine IFN- $\gamma$ and human EGF were purchased from PeproTech (catalog AF-310-05 and AF-100-15, respectively), and 293 and 293T cells (RCB1637 and RCB2202, respectively; Riken RBC) were cultured in DMEM supplemented with 10\% FBS. Expression vectors (pcDNA3) containing Samd9L were induced using Lipofectamine 2000, and cells were cultured for 48 hours.

IHC- $p$. Formalin-fixed and paraffin-embedded organs were sectioned at a $3 \mu \mathrm{m}$ thickness. Before staining, the paraffin was removed in xylene. Tissue sections were then rehydrated through a graded ethanol series and rinsed in $\mathrm{H}_{2} \mathrm{O}$. Antigen retrieval was performed by boiling in antigen unmasking solution (Immunosaver; Nisshin EM). Tissue sections were then incubated overnight at $4^{\circ} \mathrm{C}$ with primary antibodies in $0.1 \%$ Tween20/PBS. HRP-conjugated secondary antibody/ DAB detection was performed using kits (Histofine series; Nichirei Biosciences) according to the manufacturer's instructions, followed by PAS staining (where indicated) and hematoxylin counterstaining. Primary antibodies used for IHC-p were as follows: rabbit anti-mouse EGFR (at 1:25), rabbit anti-Ship2 (catalog 166916; Abcam; at 1:50), rat anti-Lamp1 (catalog sc19992; Santa Cruz Biotechnology Inc.; at 1:50), and mouse anti-mouse Samd9L (clone A6m) at a 1:25 dilution. This IgG monoclonal antibody was raised against the GST-fusion protein of mouse Samd9L (aa 69-130) and purified from the conditioned medium of hybridoma by Protein Purify Industrial Co. The contrast in images was enhanced using ImageJ software (NIH).

IF, D-PLA, and IHC for frozen sections. Cells cultured on coverslips, splenocyte suspensions, or mouse organs frozen at $-80^{\circ} \mathrm{C}$ in embedding medium (OCT compound; catalog 4583; Sakura Finetek) and sectioned at a $5 \mu \mathrm{m}$ thickness were fixed with $4 \%$ paraformaldehyde in PBS and permeabilized with $1 \%$ Triton X-100 in PBS. Cells or tissue sections were then incubated with primary antibodies at RT for 1 hour in PBS supplemented with $5 \%$ goat serum, followed by incubation with fluorescent-conjugated secondary antibody under the same conditions as the primary antibody if primary antibodies were unconjugated with a fluorescent dye. Stained splenocytes were collected on a glass slide with a cytocentrifuge. For a D-PLA system (Sigma-Aldrich), a set of 2 secondary antibodies in which one was conjugated to a minus strand PLA probe and the other was conjugated to a plus strand PLA probe were applied according to the manufacturer's instructions. Stained cells on cover glasses or slide glasses were then mounted in antifade mounting medium with or without DAPI (Vectashield; catalog H-1200 or H-1000, respectively; Vector Laboratories). Images were visualized using a confocal laser scanning microscope
(Fluoview FV1000; Olympus) and captured using software provided by the manufacturer. Image brightness and contrast were edited using ImageJ software. The primary antibodies used were as follows: BV421-conjugated rat anti-Ter119 (catalog 566248; BD Biosciences - Pharmingen; at 1:50), HiLyte Fluo555-conjugated (FL555-conjugated) anti-mouse Samd9L (A6m) at 1:50, Cy5-conjugated mouse anti-TfR (TIB-219; Bio X Cell; at 1:100), Alexa Fluor 488-conjugated mouse anti-clathrin heavy chain (catalog MA1065A488; Invitrogen; at 1:50), and rabbit anti-Picalm (catalog ab172962; Abcam; at 1:50). In addition, CF488-conjugated anti-EGFR, FL555-conjugated antiShip2, and anti-Lamp1 antibodies were used at 1:100. Secondary antibodies used were Alexa Fluor 488-conjugated goat anti-rabbit or Alexa Fluor 555-conjugated goat anti-rat IgG (catalog A11008 or A21434, respectively; Invitrogen; at 1:1000). Fluorescent dyes were conjugated with antibodies using kits (CF488A Mix-n-Stain Antibody Labeling Kit; catalog 92273; Biotium; HiLyte Fluor 555 Labeling Kit; catalog LK14; Dojindo Molecular Technologies). Filamentous actin was stained by iFluor488-conjugated phalloidin (catalog ab176753; Abcam; at 1:1000).

Fluoppi assay. Human SAMD9, SAMD9L, and SHIP2 genes were cloned into pAsh-MCL, phAG-MNL, and phAG-MCL vectors (Medical and Biological Laboratories), respectively. The cDNAs of SAMD9 and SAMD9L were obtained from Kazusa Genome Technologies Inc. phAG and pAsh vectors were cotransfected to 293T cells using Lipofectamine 2000, and cells were cultured for 24 hours. Medium was replaced with FluoroBrite DMEM (catalog A1896701; Thermo Fisher) containing 10\% FBS and $5 \mu \mathrm{g} / \mathrm{mL}$ Hoechst 33342 (catalog H21492; Thermo Fisher), and cells were incubated for 15 minutes in a $\mathrm{CO}_{2}$ incubator. Images were visualized using a BZ-X710 microscope (Keyence).

Immunoblot analysis. Cells and tissues were lysed in NP40 lysis buffer (50 mM Tris, pH 8.0, $150 \mathrm{mM} \mathrm{NaCl}, 1 \% \mathrm{NP} 40$ ) containing protease inhibitor cocktail (catalog 4693132001; Merck) and phosphatase inhibitor (catalog 04906845 001; Sigma-Aldrich). Protein levels were quantified with a DC Protein Assay Kit (Bio-Rad). Total proteins were separated by SDS-polyacrylamide gel electrophoresis and transferred electrophoretically to a polyvinylidene difluoride membrane (Immobilon-P; Merck), which was blocked in 5\% BSA with Tris-buffered saline and $0.1 \%$ Tween 20 . The blots were then stained with primary antibodies, followed by horseradish peroxidase-conjugated anti-rabbit or anti-mouse immunoglobulin secondary antibodies and subjected to chemiluminescence detection (GE Healthcare) according to the manufacturer's instructions. The primary antibodies used in this study were as follows: rabbit polyclonal antibody against mouse Samd9L (aa 69-130) raised in our institute as previously described (16) at 1:500, rabbit anti-pan- or phospho-Akt (C67E7 or D9E; catalog 4691 or 4060, respectively; Cell Signaling Technology; at 1:500), rat antiLamp1 (at 1:500) and mouse anti- $\beta$-actin (C4; catalog MAB1501R; Sigma-Aldrich; at 1:500). Image J software was used to enhance contrast and measure the intensity of protein bands.

Interphase in situ hybridization. Lineage-specific bone marrow cells were obtained by methods described in Bone marrow isolation and culture using antibodies against Gra-1 and Mac-1 for granulocyte-macrophage fraction, Ter119 for erythroid lineage, and B220 and $\mathrm{CD} 3 \varepsilon$ for lymphoid cells. Sample slides prepared by standard cytogenetic methods were pretreated in $2 \times \mathrm{SSC}, \mathrm{pH} 7.0$ at $37^{\circ} \mathrm{C}$ for 2 minutes, dehydrated in $70 \%, 85 \%$, and $100 \%$ ethanol for 1 minute each, and air dried at RT. BAC DNA containing mouse Samd9L gene 
(RP11-680N14, BACPAC Resource Center) was labeled using a kit (FISHbright, catalog FLK-005; Kreatech Biotechnology) according to the manufacturer's directions. Probes were prepared by adding $25 \times$ excess of mouse $\mathrm{C}_{0} \mathrm{t}-1$ DNA (catalog 18440016; Thermo Fisher Scientific) to the labeled probe, ethanol precipitated, and resuspended in hybridization solution supplied by the manufacturer. Codenaturation was performed by applying probe mix to slides, which were then covered with a glass coverslip. Slides were heated on a hot plate at $75^{\circ} \mathrm{C}$ for 5 minutes, followed by overnight incubation on a hot plate at $37^{\circ} \mathrm{C}$. Slides were washed in $0.4 \times \mathrm{SSC} / 0.3 \% \mathrm{NP}-40$ for 2 minutes at $72^{\circ} \mathrm{C}$ $\left( \pm 1^{\circ} \mathrm{C}\right)$, and then in $2 \times \mathrm{SSC} / 0.1 \% \mathrm{NP}-40$ for 1 minute at RT. Slides were counterstained with DAPI and visualized using a confocal laser scanning microscope.

Statistics. Statistical significance for multiple comparisons was determined by Tukey's test (Figure 2B, Figure 3, B-E, and G, and Figure $5 \mathrm{E}$ ) or the Tukey-Kramer test (when the sample sizes were unequal; Figure 1, D and F, Figure 2, A and C, and Figure 3F). Significance between control and test groups was calculated with the logrank test (Figure 1E), 2-tailed Student's $t$ test (Figure 4B), or $\chi^{2}$ test (Figure 6B). All statistical analyses were carried out using Prism 8 (GraphPad Software).

Animal studies. All mice were kept according to guidelines of the Institute of Laboratory Animal Science, Hiroshima University. The Animal Care Committee at the Japanese Foundation for Can- cer Research approved all murine studies. All mice were housed in groups of 3 to 5 animals per cage and maintained on a regular 12-hour light/12-hour dark cycle at a constant $20-25^{\circ} \mathrm{C}$.

\section{Author contributions}

TI and AN conceived and designed the study. AN supervised all animal studies and FCM analysis. AN, MN, and SS performed animal experiments. TI, AK, HO, HM, AY, and MN performed histological and biochemical experiments. TI supervised all experimental and analytic aspects of this work. TI and AN acquired funding. TI wrote the manuscript with input from all authors.

\section{Acknowledgments}

We are grateful to T. Kusaba for useful discussion. We thank N. Yamasaki, K. Fujioka, Y. Nakata, and Y. Ozaki for excellent technical assistance. This work was supported by JSPS KAKENHI grant number JP18H02838, the Takeda Science Foundation, and the Japan Leukemia Research Fund.

Address correspondence to: Toshiya Inaba, Department of Molecular Oncology and Leukemia Program Project, Research Institute for Radiation Biology and Medicine, Hiroshima University, 1-2-3 Kasumi, Minami-ku, Hiroshima 734-8553, Japan. Phone 81.82.257.5834; Email: tinaba@hiroshima-u.ac.jp.
1. Bluteau $\mathrm{O}$, et al. A landscape of germline mutations in a cohort of inherited bone marrow failure patients. Blood. 2018;131(7):717-732.

2. Inaba T, et al. The enigma of monosomy 7. Blood. 2018;131(26):2891-2898.

3. Narumi S, et al. SAMD9 mutations cause a novel multisystem disorder, MIRAGE syndrome, and are associated with loss of chromosome 7. Nat Genet. 2016;48(7):792-797.

4. Buonocore F, et al. Somatic mutations and progressive monosomy modify SAMD9-related phenotypes in humans. J Clin Invest. 2017;127(5):1700-1713.

5. Chen DH, et al. Ataxia-pancytopenia syndrome is caused by missense mutations in SAMD9L. Am J Hum Genet. 2016;98(6):1146-1158.

6. Gorcenco S, et al. Ataxia-pancytopenia syndrome with SAMD9L mutations. Neurol Genet. 2017;3(5):183.

7. Pastor VB, et al. Constitutional SAMD9L mutations cause familial myelodysplastic syndrome and transient monosomy 7. Haematologica. 2018;103(3):427-437.

8. Topaz O, et al. A deleterious mutation in SAMD9 causes normophosphatemic familial tumoral calcinosis. Am J Hum Genet. 2006;79(4):759-764.

9. Pappas DJ, et al. Longitudinal system-based analysis of transcriptional responses to type I interferons. Physiol Genomics. 2009;38(3):362-371.

10. Hershkovitz D, et al. Functional characterization of SAMD9, a protein deficient in normophosphatemic familial tumoral calcinosis. J Invest Dermatol. 2011;131(3):662-669.

11. Zhang LK, et al. Identification of host proteins involved in Japanese encephalitis virus infection by quantitative proteomics analysis. J Proteome Res. 2013;12(6):2666-2678.
12. Liu J, et al. M062 is a host range factor essential for myxoma virus pathogenesis and functions as an antagonist of host SAMD9 in human cells. J Virol. 2011;85(7):3270-3282.

13. Nounamo B, et al. An interaction domain in human SAMD9 is essential for myxoma virus host-range determinant M062 antagonism of host anti-viral function. Virology. 2017;503:94-102.

14. Meng X, et al. A paralogous pair of mammalian host restriction factors form a critical host barrier against poxvirus infection. PLoS Pathog. 2018;14(2):1006884.

15. Asou $\mathrm{H}$, et al. Identification of a common microdeletion cluster in 7q21.3 subband among patients with myeloid leukemia and myelodysplastic syndrome. Biochem Biophys Res Commun. 2009;383(2):245-251.

16. Nagamachi A, et al. Haploinsufficiency of SAMD9L, an endosome fusion facilitator, causes myeloid malignancies in mice mimicking human diseases with monosomy 7. Cancer Cell. 2013;24(3):305-317.

17. Shima $\mathrm{H}$, et al. Two patients with MIRAGE syndrome lacking haematological features: role of somatic second-site reversion SAMD9 mutations. J Med Genet. 2018;55(2):81-85.

18. Perisa MP, et al. A novel SAMD9 variant identified in patient with MIRAGE syndrome: further defining syndromic phenotype and review of previous cases. Pediatr Blood Cancer. 2019;66(7):27726.

19. Mengen E, Kucukcongar Yavas A. A rare etiology of 46,XY disorder of sex development and adrenal insufficiency: a case of MIRAGE syndrome caused by mutations in the SAMD9 gene. JClin Res Pediatr Endocrinol. 2019;12(2):206-211.

20. Csillag B, et al. Somatic mosaic monosomy 7 and UPD7q in a child with MIRAGE syndrome caused by a novel SAMD9 mutation. Pediatr Blood Cancer. 2019;66(4):27589.

21. Sarthy J, et al. Poor outcome with hematopoietic stem cell transplantation for bone marrow failure and MDS with severe MIRAGE syndrome phenotype. Blood Adv. 2018;2(2):120-125.

22. Kim YM, et al. A case of an infant suspected as IMAGE syndrome who were finally diagnosed with MIRAGE syndrome by targeted Mendelian exome sequencing. BMC Med Genet. 2018;19(1):35.

23. Schwartz JR, et al. Germline SAMD9 mutation in siblings with monosomy 7 and myelodysplastic syndrome. Leukemia. 2017;31(8):1827-1830.

24 . Yoshizaki K, et al. MIRAGE syndrome with recurrent pneumonia probably associated with gastroesophageal reflux and achalasia: a case report. Clin Pediatr Endocrinol. 2019;28(4):147-153.

25. Roucher-Boulez F, et al. Reversion SAMD9 mutations modifying phenotypic expression of MIRAGE syndrome and allowing inheritance in a usually de novo disorder. Front Endocrinol (Lausanne). 2019;10:625.

26. Cheah JJC, et al. A novel germline $S A M D 9 L$ mutation in a family with ataxia-pancytopenia syndrome and pediatric acute lymphoblastic leukemia. Haematologica. 2019;104(7):318-321.

27. Aida T, et al. Cloning-free CRISPR/Cas system facilitates functional cassette knock-in in mice. Genome Biol. 2015;16:87.

28. Jiang Q, et al. The Samd9L gene: transcriptional regulation and tissue-specific expression in mouse development. J Invest Dermatol. 2011;131(7):1428-1434.

29. Socolovsky M, et al. Ineffective erythropoiesis in Stat5a(-/-) $5 \mathrm{~b}(-/-)$ mice due to decreased survival of 
early erythroblasts. Blood. 2001;98(12):3261-3273.

30. Chen $\mathrm{K}$, et al. Resolving the distinct stages in erythroid differentiation based on dynamic changes in membrane protein expression during erythropoiesis. Proc Natl Acad Sci U S A. 2009;106(41):17413-17418.

31. Suzuki M, et al. The clathrin assembly protein PICALM is required for erythroid maturation and transferrin internalization in mice. PLoS One. 2012;7(2):31854

32. Ishikawa Y, et al. Role of the clathrin adaptor PICALM in normal hematopoiesis and polycythemia vera pathophysiology. Haematologica. 2015;100(4):439-451.

33. Tebar F, et al. Clathrin assembly lymphoid myeloid leukemia (CALM) protein: localization in endocytic-coated pits, interactions with clathrin, and the impact of overexpression on clathrin-mediated traffic. Mol Biol Cell. 1999;10(8):2687-2702.

34. Dumont C, et al. DNA-based probes for flow cytometry analysis of endocytosis and recycling. Traffic. 2017;18(4):242-249.

35. Pronk CJ, et al. Elucidation of the phenotypic, functional, and molecular topography of a myeloerythroid progenitor cell hierarchy. Cell Stem Cell. 2007;1(4):428-442.

36. Xie J, et al. How does SHIP1/2 balance PtdIns $(3,4)$ P2 and does it signal independently of its phosphatase activity. Bioessays. 2013;35(8):733-743.

37. Dyson JM, et al. The SH2-containing inositol polyphosphate 5-phosphatase, SHIP-2, binds filamin and regulates submembraneous actin. JCell
Biol. 2001;155(6):1065-1079.

38. Erneux C,et al. SHIP2 multiple functions: a balance between a negative control of PtdIns $(3,4,5)$ P3 level, a positive control of PtdIns $(3,4)$ P2 production, and intrinsic docking properties. J Cell Biochem. 2011;112(9):2203-2209.

39. Watanabe T, et al. Genetic visualization of protein interactions harnessing liquid phase transitions. Sci Rep. 2017;7:46380.

40. Liu QR, et al. SHIP is a negative regulator of growth factor receptor-mediated $\mathrm{PKB} / \mathrm{Akt}$ activation and myeloid cell survival. Genes Dev. 1999;13(7):786-791.

41. Helgason CD, et al. Targeted disruption of SHIP leads to hemopoietic perturbations, lung pathology, and a shortened life span. Genes Dev. 1998;12(11):1610-1620.

42. Sleeman MW, et al. Absence of the lipid phosphatase SHIP2 confers resistance to dietary obesity. Nat Med. 2005;11(2):199-205.

43. Yan YC, et al. Testis epidermal growth factor and spermatogenesis. Arch Androl. 1998;40(2):133-146.

44. Li X, et al. Epidermal growth factor regulates the development of stem and progenitor Leydig cells in rats. J Cell Mol Med. 2020;24(13):7313-7330.

45. Zhou R, et al. The roles and mechanisms of Leydig cells and myoid cells in regulating spermatogenesis. Cell Mol Life Sci. 2019;76(14):2681-2695.

46. Chen P, et al. Stem Leydig cells in the adult testis: characterization, regulation and potential applications. Endocr Rev. 2020;14(1):22-32.

47. Zhang Z, et al. Targeted inactivation of EGF receptor inhibits renal collecting duct devel- opment and function. JAm Soc Nephrol. 2010;21(4):573-578.

48. Nagamachi A, et al. Kinetics of cytokine receptor internalization under steady-state conditions affects growth of neighboring blood cells. Haematologica. 2020;105(7):325-327.

49. Lu Y, Waller EK. Dichotomous role of interferon-gamma in allogeneic bone marrow transplant. Biol Blood Marrow Transplant. 2009;15(11):1347-1353.

50. Nagamachi A, et al. A 5' untranslated region containing the IRES element in the Runx1 gene is required for angiogenesis, hematopoiesis and leukemogenesis in a knock-in mouse model. Dev Biol. 2010;345(2):226-236.

51. Breggia AC, Himmelfarb J. Primary mouse renal tubular epithelial cells have variable injury tolerance to ischemic and chemical mediators of oxidative stress. Oxid Med Cell Longev. 2008;1(1):33-38.

52. Morita S, et al. Plat-E: an efficient and stable system for transient packaging of retroviruses. Gene Ther. 2000;7(12):1063-1066.

53. Hahn WC, et al. Enumeration of the simian virus 40 early region elements necessary for human cell transformation. Mol Cell Biol. 2002;22(7):2111-2123.

54. Mancini E, et al. FOG-1 and GATA-1 act sequentially to specify definitive megakaryocytic and erythroid progenitors. EMBO J. 2012;31(2):351-365.

55. Li Z, et al. High ambient temperature disrupted the circadian rhythm of reproductive hormones and changed the testicular expression of steroidogenesis genes and clock genes in male mice. Mol Cell Endocrinol. 2020;500:110639. 